ARTICLE

https://doi.org/10.1038/s41467-019-10849-y

\title{
Mutations in SMARCB1 and in other Coffin-Siris syndrome genes lead to various brain midline defects
}

\author{
Alina Filatova (1) ${ }^{1}$, Linda K. Rey², Marion B. Lechler ${ }^{1}$, Jörg Schaper ${ }^{3}$, Maja Hempel ${ }^{4}$, Renata Posmyk ${ }^{5}$, \\ Krzysztof Szczaluba ${ }^{6}$, Gijs W.E. Santen7, Dagmar Wieczorek ${ }^{2}$ \& Ulrike A. Nuber (1) ${ }^{1}$
}

Mutations in genes encoding components of BAF (BRG1/BRM-associated factor) chromatin remodeling complexes cause neurodevelopmental disorders and tumors. The mechanisms leading to the development of these two disease entities alone or in combination remain unclear. We generated mice with a heterozygous nervous system-specific partial loss-offunction mutation in a BAF core component gene, Smarcb1. These Smarcb1 mutant mice show various brain midline abnormalities that are also found in individuals with Coffin-Siris syndrome (CSS) caused by SMARCB1, SMARCE1, and ARIDIB mutations and in SMARCB1-related intellectual disability (ID) with choroid plexus hyperplasia (CPH). Analyses of the Smarcb1 mutant animals indicate that one prominent midline abnormality, corpus callosum agenesis, is due to midline glia aberrations. Our results establish a novel role of Smarcb1 in the development of the brain midline and have important clinical implications for BAF complexrelated ID/neurodevelopmental disorders.

\footnotetext{
${ }^{1}$ Stem Cell and Developmental Biology, Technical University Darmstadt, Darmstadt 64287, Germany. ${ }^{2}$ Institute of Human Genetics, Medical Faculty, Heinrich Heine University, Düsseldorf 40225, Germany. ${ }^{3}$ Department of Diagnostic and Interventional Radiology, Medical Faculty, Heinrich Heine University, Düsseldorf 40225, Germany. ${ }^{4}$ Institute of Human Genetics, University Medical Center Hamburg-Eppendorf, Hamburg 20246, Germany. ${ }^{5}$ Podlaskie Medical Centre "GENETICS" Bialystok and Department of Perinatology and Obstetrics, Medical University of Bialystok, Bialystok 15-276, Poland. ${ }^{6}$ Department of Medical Genetics, Medical University Warsaw, Warsaw 02-106, Poland. 7 Department of Clinical Genetics, Leiden University Medical Center, Leiden 2333 ZA, Netherlands. Correspondence and requests for materials should be addressed to U.A.N. (email: nuber@bio.tu-darmstadt.de)
} 
$\mathrm{n}$ the course of mammalian development, a multitude of cell type specification, maintenance, and differentiation events takes place, governed by specific gene expression patterns. Chromatin remodeling complexes play an essential role in controlling the establishment and maintenance of gene activities. The relevance of these complexes is reinforced by the consequences of aberrations in their components.

Mutations in genes encoding components of the ATPdependent chromatin remodeling BAF complex (mammalian SWI/SNF complex) are found in two distinct disease types: intellectual disability (ID)/neurodevelopmental disorders and tumors. They belong to the most frequently mutated genes in human ID, and close to $20 \%$ of all human cancers harbor mutations in these genes ${ }^{1-4}$.

One of the disorders caused by mutations in BAF complex component genes is Coffin-Siris syndrome (CSS), a congenital malformation syndrome characterized by severe developmental delay affecting motor and intellectual functions, growth impairment, hypotonia, a distinct facial appearance with coarse features, feeding difficulties in infancy, and hypoplastic to absent fifth distal phalanges, fingernails and toenails ${ }^{5}$. Heterozygous germline mutations in six genes encoding BAF complex components have been found in CSS: ARID1A, ARID1B, DPF2, SMARCA4, SMARCE1, and SMARCB1 (also referred to as BAF47, INI1, SNF5 $)^{6-9}$. Several of these genes are also associated with other ID/ neurodevelopmental disorders, and owing to overlapping clinical features, their differentiation from CSS can be difficult ${ }^{10}$. A particular heterozygous SMARCB1 mutation has been described in individuals with severe ID and choroid plexus hyperplasia $(\mathrm{CPH})$ and we refer to this condition as SMARCB1-related ID$\mathrm{CPH}^{11}$. It remains unresolved how alterations in BAF complex genes lead to the specific developmental brain defects seen in affected individuals. Heterozygous germline mutations in these genes also predispose to diverse tumors, including brain tumors $^{2,12}$, and it is unclear how such distinct disease entities can be caused by mutations in identical genes ${ }^{3}$.

We generated mice (Smarcb1 $1^{+/ i n v} \mathrm{NesCre}^{+/-}$) with a heterozygous reversible Smarcb1 disruption in neural stem/progenitor cells. To our knowledge, this is the first mouse model that recapitulates brain defects seen in SMARCB1-related CSS and ID-CPH and is based on a monoallelic Smarcb1 mutation. Smarcb1 $1^{+/ i n v} \mathrm{NesCre}{ }^{+/-}$mice show brain midline abnormalities and we identified similar alterations in CSS individuals. The spectrum of brain midline abnormalities in these individuals is much broader than described for CSS so far and includes reduction or absence of forebrain commissures, absence or hypoplasia of the septum pellucidum, choroid plexus (CP) hyperplasia, and cerebellar vermis hypoplasia. A prominent aberration in Smarcb1 mutant animals, agenesis of the corpus callosum (CC), can be explained by defects in midline radial glial cells (RGCs). Interestingly, Smarcb1 transcript levels are reduced by about $30 \%$ in embryonic brain tissue of these mutant mice, whereas there is no reduction in Smarcb1 transcript levels in heterozygous germline Smarcb1 knockout animals $\left(\operatorname{Smarcb1} 1^{+/-}\right)$. Smarcb1 $1^{+/-}$mice do not show any brain abnormalities but are prone to develop malignant tumors, presumably upon loss-offunction of the second Smarcb1 allele ${ }^{13}$. Based on our results and on the review of individuals with SMARCB1 mutations in the literature, we suggest that the development of ID/neurodevelopmental disorders or malignant tumors could depend on a transcriptional compensation by the second intact SMARCB1 allele.

\section{Results}

Neurodevelopmental phenotypes in Smarcb1 ${ }^{+/ i n v} \mathrm{NesCre}^{+/-}$ mice. We generated mice with a heterozygous Smarcb1 disruption in the nervous system (Smarcb1 $1^{+/ i n v} \mathrm{NeSCr}^{+/-}$) by crossing Smarcb1 $1^{\text {inv/inv }}$ animals, in which exon 1 is flanked by loxP sites of opposite orientation ${ }^{14}$ (originally termed Snf5 $5^{i n / i n v}$ ), with $\mathrm{NesCr}^{+/-}$animals expressing Cre recombinase under the control of the rat nestin promoter and nervous system-specific enhancer ${ }^{15}$ (Fig. 1). Cre activity in these mice starts in nervous system tissue at embryonic day $10.5(\mathrm{E} 10.5)^{16}$. The majority of targeted cells are therefore RGCs. Cre-mediated recombination leads to an inversion of the floxed sequence in Smarcb1+/inv NesCre ${ }^{+/-}$animals, resulting in an inactivation of this allele ${ }^{14}$ (Fig. 1f). The inversion is reversible and continues forth and back as long as Cre is expressed, theoretically leading to about $50 \%$ of the Nestin-expressing cells possessing an active and $50 \%$ possessing an inactive Smarcb1 allele, in addition to the second wildtype allele. Breedings with male or female $\mathrm{NesCr}^{+/-}$mice resulted in Smarcb1 $1^{+/ i n v}$ offspring according to Mendelian ratios ( 50\% Smarcb1 $1^{+/ i n v} \mathrm{NesCre}{ }^{+/-}$and $\sim 50 \%$ Smarcb1 $1^{+/ i n v}$ $\left.\mathrm{NesCre}{ }^{-/-}\right)$. Smarcb1 $1^{+/ i n v} \mathrm{Nes} C r e^{-/-}$animals are named controls since they lack the NesCre transgene and do not show any obvious differences to wild-type mice.

Smarcb1 $1^{+/ i n v} \mathrm{NesCr} e^{+/-}$mice, referred to as mutant animals, were smaller (Fig. 1a) and had a lower body weight in comparison to littermate controls (Supplementary Fig. 1a). Very striking was their overall smaller brain with cerebral hemispheres widely separated from each other (Fig. 1b). The microcephaly was already apparent in utero: at E14.5, the brain weight of mutants was reduced by $41 \%$ in comparison to littermate controls, whereas there was no difference in body weight (Supplementary Fig. 1b, c). Brain phenotypes ranged from moderate ones with cerebral hemispheres rostrally, but not caudally connected, to extreme ones with rostral and caudal cerebral hemispheres fully separated, being only connected by thin dorsal membrane-like structures (Supplementary Fig. 1d). About 80\% of mutant animals died before postnatal week 9 , and such animals typically showed more severe brain phenotypes. The remaining ones survived for $>1$ year (Supplementary Fig. 1e) and were fertile (Supplementary Fig. 2a). To exclude that the brain phenotypes are caused by the NesCre allele, we performed additional breeding with mice of different genotypes (Supplementary Fig. 2a). Again, Smarcb1 $1^{+/ i n v} \mathrm{NesCre}{ }^{+/-}$animals were affected but not Smarcb1 $1^{+/+} \mathrm{NesCr}^{+/-}$as well as other genotypes. In the course of our whole study, we once obtained a stillborn animal with a Smarcb1 ${ }^{\text {inv/inv }} \mathrm{NesCre}{ }^{+/-}$genotype. Embryonic brains of such mice with two mutant Smarcb1 alleles were of severely reduced size (Supplementary Fig. 2b).

The cerebellum of 22 investigated postnatal mutants was hypoplastic and showed a reduced foliation (Fig. 1b, d). In addition, 19 of the 22 animals presented with particular cerebellar midline defects-macroscopically they showed a midline fusion of the cerebellar hemispheres without any longitudinal fissures (arrowheads in Fig. 1d). In the majority of cases, no vermis was seen at the cerebellar surface. In two cases, the cerebellar hemispheres were widely separated with only a superior tissue bridge present in between (arrow in Fig. 1d). Analyses of tissue sections confirmed a midline fusion of the cerebellar hemispheres and revealed a midline structure resembling a smaller vermis (Fig. 1e); however, no fissure separated this structure from the hemispheres as it is normally the case. We interpret this phenotype as a fusion/continuity of the vermis with the cerebellar hemispheres.

To further characterize the forebrain midline defects, we analyzed postnatal brain tissue and sections thereof (summarized in Fig. 1c). All 16 investigated mutants lacked the hippocampal commissure, 9 lacked the caudal CC, 6 showed a complete CC agenesis, and an intact CC was present in 1 case (Figs. 1c and $2 \mathrm{~b}-\mathrm{d})$. The anterior commissure was absent in 6 of 16 cases (Figs. $1 \mathrm{c}$ and $2 \mathrm{c}, \mathrm{d}$ ). Above the third ventricle, the medial cortex 
a

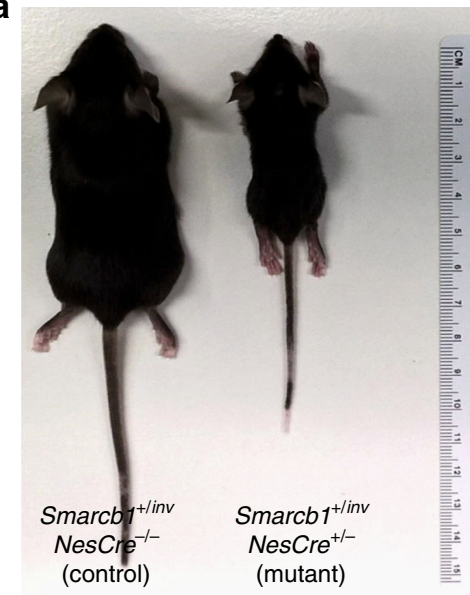

\begin{tabular}{|l|c|}
\hline Clfactory bulbs present & $22 / 22$ \\
\hline Cerebral hemispheres & $2 / 22$ \\
\hline Hemispheres partially fused (rostrally) & $20 / 22$ \\
\hline Hemispheres not fused & \\
\hline Corebral commissures & $9 / 16$ \\
\hline Partial CC agenesis & $6 / 16$ \\
\hline Anterior commissure (AC) & \\
\hline AC present & $10 / 16$ \\
\hline AC absent & $6 / 16$ \\
\hline Hippocampal commissure (HC) & $16 / 16$ \\
\hline HC agenesis & $22 / 22$ \\
\hline Cerebellum & $22 / 22$ \\
\hline Cerebellar hypoplasia & $21 / 22$ \\
\hline Reduced lobulation & $19 / 22$ \\
\hline Vermis hypoplasia & $16 / 22$ \\
\hline Fusion of cerebellar hemispheres & $3 / 22$ \\
\hline Complete fusion & \\
\hline Partial fusion & \\
\hline
\end{tabular}

f

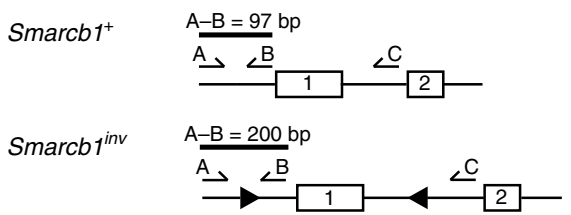

Smarcb $1^{\text {inv }} \quad \mathrm{A}-\mathrm{B}=200 \mathrm{bp}$

Cre+
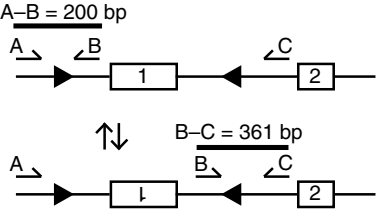

Genomic DNA

$$
c^{1} r^{2} c^{2} c^{3} r^{2} r^{3} c^{d} r^{x} r^{6}
$$

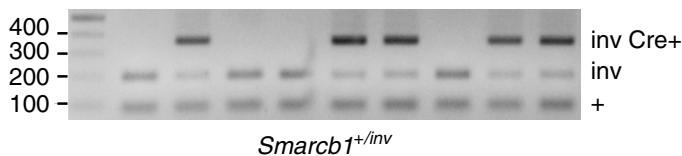

edges were located far apart from each other and only connected by thin membrane-like structures (compare Fig. $2 \mathrm{a}$ to Fig. $2 \mathrm{~b}-\mathrm{d}$ ). In severe cases, this separation continued in a rostral direction (Fig. 2c, d). Furthermore, a midline cleft separated the left and right half of the diencephalon (arrows in Fig. 2b-d). b
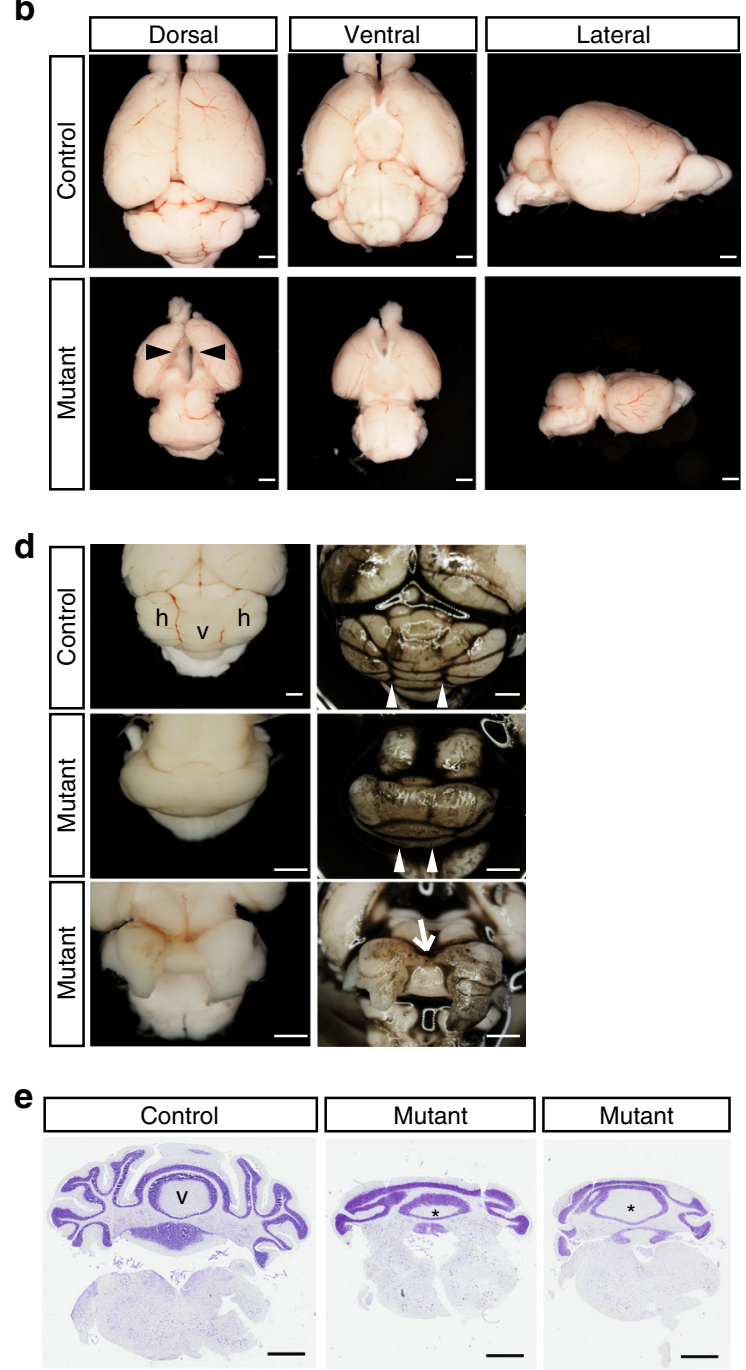

g

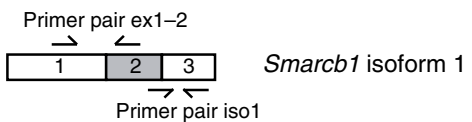

Primer pair ex1-2
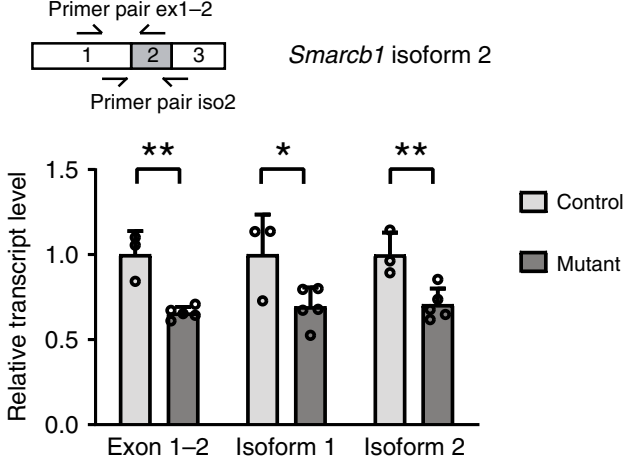

To better understand the consequences of the monoallelic reversible Smarcb1 exon 1 inversion, we analyzed Smarcb1 genomic DNA and transcript levels in E14.5 forebrain tissue. These experiments confirmed a Cre-mediated inversion of Smarcb1 exon 1 (Fig. 1f) and revealed that Smarcb1 transcript 
Fig. 1 Phenotypic and genetic analyses of mutant and control mice. a Control and mutant animal (age: 3 weeks). b Brains of 3-week-old mutant mice are smaller and their cerebral hemispheres are separated by a midline gap (arrowheads). c Summary of brain phenotypes in mutant animals. d Cerebelli of 3-4-week-old control and mutant animals; right panel: brains were ink-stained for the visualization of fissures; $h$ cerebellar hemisphere, $v$ cerebellar vermis. Note the smaller size and reduced foliation of mutant cerebelli. Upper panel: control brain with longitudinal (anterior-posterior) fissures (arrowheads) separating the vermis from the two lateral hemispheres. Middle panel: mutant cerebellum with lack of longitudinal fissures (arrowheads) and fusion of the two lateral hemispheres (the majority of cases). Lower panel: mutant cerebellum with separated hemispheres that are only rostrally connected (arrows). e Nissl-stained coronal sections of control and mutant cerebelli (3-4 weeks of age). Note the midline fusion of lateral hemisphere lobules in the mutants. $v$ cerebellar vermis; asterisk $\left({ }^{\star}\right)$ vermislike midline structure. Scale bars in $\mathbf{b}, \mathbf{d}, \mathbf{e}: 1 \mathrm{~mm}$. $\mathbf{f}$ Inversion of Smarcb1 exon 1 in genomic DNA from E14.5 mutant and control forebrain tissue detected by polymerase chain reaction (PCR). Three primer pairs are used in one reaction, leading to amplification of a 97-bp product in case of the wild-type allele $\left(\right.$ Smarcb $1^{+}$), of a 200-bp product in case of the active, non-inverted, floxed allele (Smarcb7inv) due to loxP site and extra DNA sequences, and of a 361-bp product in case of the inactive inverted allele ( $\mathrm{Smarcb} 7^{\text {inv }} \mathrm{Cre}+$ ). Gel electrophoresis of the PCR products shows the presence of inverted and non-inverted alleles in all mutant samples (m1-m5). g Smarcb1 transcript levels in E14.5 control (c2-c4) and mutant (m1-m5) forebrain tissue determined by quantitative reverse transcriptase-PCR. Primers binding to exons 1 and 2 and primers that specifically amplify one of the two Smarcb1 isoforms differing in exon 2 length were applied. Significantly reduced levels of all three cDNA PCR products were found in mutant (five animals) compared to control (three animals) samples. All bars display the mean with standard deviations. ${ }^{\star} p \leq 0.05,{ }^{\star \star} p \leq 0.01$ (unpaired two-tailed Student's $t$ test). Source data are provided as a Source Data file

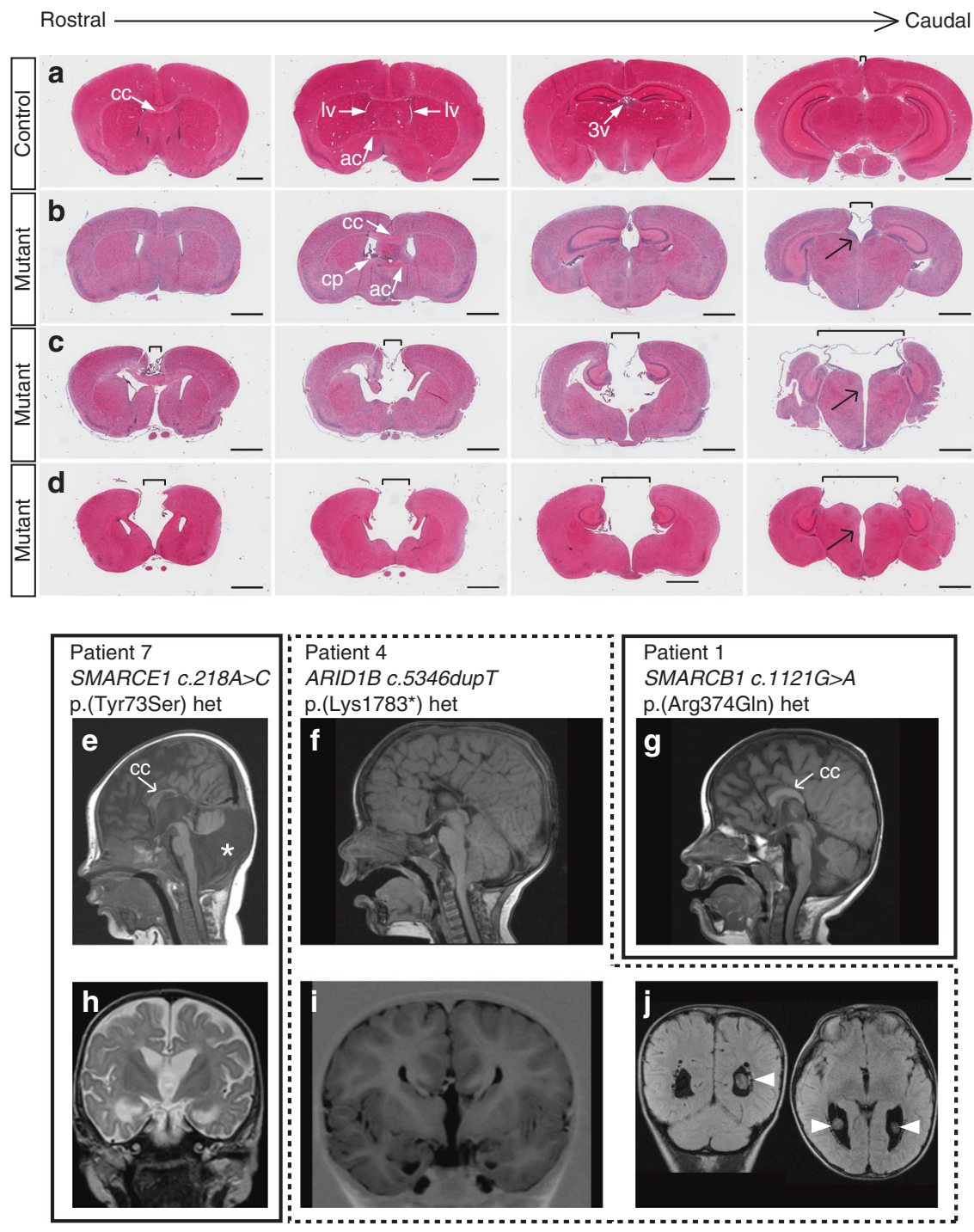

Fig. 2 Midline brain defects in mutant mice and in Coffin-Siris syndrome (CSS) patients. a-d Hematoxylin-eosin-stained coronal sections of 3-4-week-old postnatal animals. One control animal (a) and three mutant animals with increasing phenotypic severity (b-d) are shown. Note the increased distance between the cerebral hemispheres (brackets) in mutant animals that is most severe in caudal sections at the level of the diencephalon. Black arrows point to a midline cleft between the two halves of the thalamus. ac anterior commissure, cc corpus callosum, $\mathrm{cp}$ choroid plexus, Iv lateral ventricle, $3 \mathrm{v}$ third ventricle. Scale bars: $1 \mathrm{~mm}$. e-j Magnetic resonance imaging scans of three CSS individuals with a germline mutation in SMARCE1 (patient 7, e, h), ARID1B (patient $4, \mathbf{f}, \mathbf{i}, \mathbf{j}$ ), and SMARCB1 (patient 1, g). Note the short and thin CC in e, hypoplastic septum pellucidum, small anterior and hippocampal commissures (h) and Dandy-Walker variant (asterisk in $\mathbf{e}$ ) with a large posterior fossa, vermis hypoplasia, and cerebellar dysplasia in patient 7. Patient 4 lacks the CC, the anterior and hippocampal commissures, and the septum pellucidum (f, i). Moreover, a voluminous CP is present (arrowheads in $\mathbf{j}$ ). $A$ short and stubby CC is present in patient $1(\mathbf{g})$ 


\section{Table 1 Brain MRI findings in CSS individuals}

\begin{tabular}{|c|c|c|c|c|c|c|c|}
\hline No. & Mutation & CC & AC & HC & $\begin{array}{l}\text { Septum } \\
\text { pellucidum }\end{array}$ & CP & Cerebellum \\
\hline 1 & 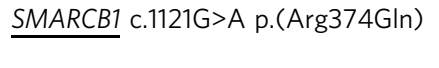 & $\begin{array}{l}\text { Short } \\
\text { stubby }\end{array}$ & Not visible & Not visible & Present & Normal & Normal \\
\hline 8 & 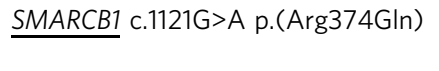 & $\begin{array}{l}\text { Short } \\
\text { stubby }\end{array}$ & Not visible & Not visible & Present & Normal & Normal \\
\hline 9 & $\frac{\text { SMARCB1 c.1091_1093delAGA }}{\text { p.(Lys364del) }}$ & Short & Normal & Normal & Present & Normal & $\begin{array}{l}\text { Large posterior fossa, } \\
\text { hypoplastic vermis, cerebellar } \\
\text { hypoplasia }\end{array}$ \\
\hline 10 & $\frac{\text { SMARCB1 c.1091_1093delAGA }}{\text { p.(Lys364del) }}$ & Short thin & Small & Small & Normal & Normal & $\begin{array}{l}\text { Enlarged fourth ventricle, mild } \\
\text { vermis hypoplasia }\end{array}$ \\
\hline 11 & SMARCB1 c.1121G>A p.(Arg374GIn) & Short thin & Normal & Normal & Normal & Normal & Normal \\
\hline 2 & $\begin{array}{l}\overline{\text { ARID1B c.5961_5964delGAGA }} \\
\left.\text { p.(Arg1988Serfs }{ }^{\star} 32\right)\end{array}$ & Normal & Normal & Normal & Present & Normal & Normal \\
\hline 3 & $\frac{\text { ARID1B c.3604_3610dupTCCATGG }}{\text { p.(Ala1204Valfs*8) }}$ & $\begin{array}{l}\text { Short } \\
\text { stubby }\end{array}$ & Small & Small & Present & Normal & Normal \\
\hline 4 & ARID1B c.5346dupT p.(Lys1783*) & Absent & Absent & Absent & Absent & Voluminous & Normal \\
\hline 5 & $\begin{array}{l}\overline{A R I D 1 B} \text { c.2191_2192dupAT } \\
\text { p.(Pro732Serfs¹4) }\end{array}$ & Normal & Normal & Normal & Present & Normal & Normal \\
\hline 6 & $\frac{\text { ARID1B c.5910_5928del }}{\text { p.(Pro1973Argfs } \star 29)}$ & Absent & Small & Small & Absent & Normal & Normal \\
\hline 7 & $\underline{\text { SMARCE1 c.218A>C p.(Tyr73Ser) }}$ & Short thin & Small & Small & Hypoplastic & Normal & $\begin{array}{l}\text { Large posterior fossa, vermis } \\
\text { hypoplasia, cerebellar } \\
\text { dysplasia }\end{array}$ \\
\hline
\end{tabular}

levels were significantly reduced in mutant brain tissue to about $70 \%$ of control levels (Fig. 1g).

CSS individuals show a variety of brain midline defects. Structural brain abnormalities are seen in the majority of CSS patients ${ }^{17}$; however, a detailed analysis focusing on brain midline defects has not been performed. We systematically re-evaluated brain magnetic resonance imaging (MRI) scans, which were available to us for 11 individuals with CSS. Three of them were previously reported (patients $1^{9}, 7^{9}, 10^{18}$ ), eight are newly described here (Supplementary Note 1). Of these individuals, nine exhibited brain midline defects of varying severity (Fig. $2 \mathrm{e}-\mathrm{j}$, Table 1) and had mutations in SMARCB1, SMARCE1, or $A R I D 1 B$. MRI scans of two individuals (2 and 5), both with pathogenic variants in $A R I D 1 B$, did not show any structural abnormalities.

Midline glia and interhemispheric fissure abnormalities. The development of mammalian brain midline structures involves the invagination of the roof plate. This process not only results in the formation of an interhemispheric space that separates the cerebral hemispheres but is also crucially involved in the development of the CC as the appearance of this commissure is linked to a reduction of this space. The interhemispheric space is initially filled with cells and extracellular matrix and becomes thinner during development, finally resulting in a fissure that separates the closely approximated hemispheres by only a thin layer of meningeal cells at postnatal stages.

To understand the cause of forebrain midline defects in mutant animals, we assessed their brain development. While no anatomical abnormalities were evident at E12.5, we found midline alterations at E15.5 (Supplementary Fig. 3a). Relative to the overall brain dimensions, the interhemispheric distance was increased (Supplementary Fig. 3a) and the thalamic halves were separated by a larger third ventricle space in mutant animals compared to controls (Supplementary Fig. 3a). Smarcb1 is ubiquitously expressed, and immunostaining of an E14.5 brain section confirmed the presence of Smarcb1 protein in virtually all nuclei (Supplementary Fig. 3b).

Taken together, our analyses of embryonal and postnatal tissue sections indicate an impaired midline fusion of cerebral hemispheres and of diencephalic regions, particularly in the vicinity of the telencephalic-diencephalic junction, and a failed development of commissures.

To investigate if absent commissures could be due to a failed commissural neuron generation, we analyzed the presence of these neurons by immunostaining. The majority of callosal axons in mice derives from Satb2-expressing neurons in upper cortical layers ${ }^{19,20}$. A large number of these neurons was present in postnatal day 0 ( $\mathrm{P} 0)$ mutant animals and these cells formed a layer that was correctly positioned with respect to Ctip2expressing deep layer neurons (Supplementary Fig. 4a). However, commissural axons of the CC failed to cross horizontally in mutant mice and instead deviated ventrally at the ipsilateral side (Fig. 3h).

The correct navigation and midline crossing of CC axons are controlled by neuronal and glial guidepost cells. Midline glia populations include the glial wedge $(\mathrm{GW})$, indusium griseum glia (IGG), and midline zipper glia (MZG) ${ }^{21}$. These Gfap-positive, transient cell types disappear postnatally and originate from $\mathrm{RGCs}^{22-24}$, i.e., neural stem cells that appear from E9 to E10 in the mouse and that give rise to the majority of brain neurons and macroglia 25,26 . GW cells appear at a ventral and lateral location with respect to the developing CC and prevent callosal axons from migrating ventrally ${ }^{21,22}$. IGG demarcate the developing CC dorsally ${ }^{22}$. Defects in their development are associated with CC agenesis $23,27,28$. MZG are detectable below the developing $\mathrm{CC}^{22}$. The basement membrane and leptomeningeal cells of the interhemispheric fissure, both of which are recognized by a pan-laminin-antibody, act as barrier for callosal axons to cross the midline ${ }^{24}$.

P0 mutant mice exhibited a widened interhemispheric fissure (Fig. $3 \mathrm{a}-\mathrm{j}$ ) that was not crossed by Nrp1-stained callosal axons, 

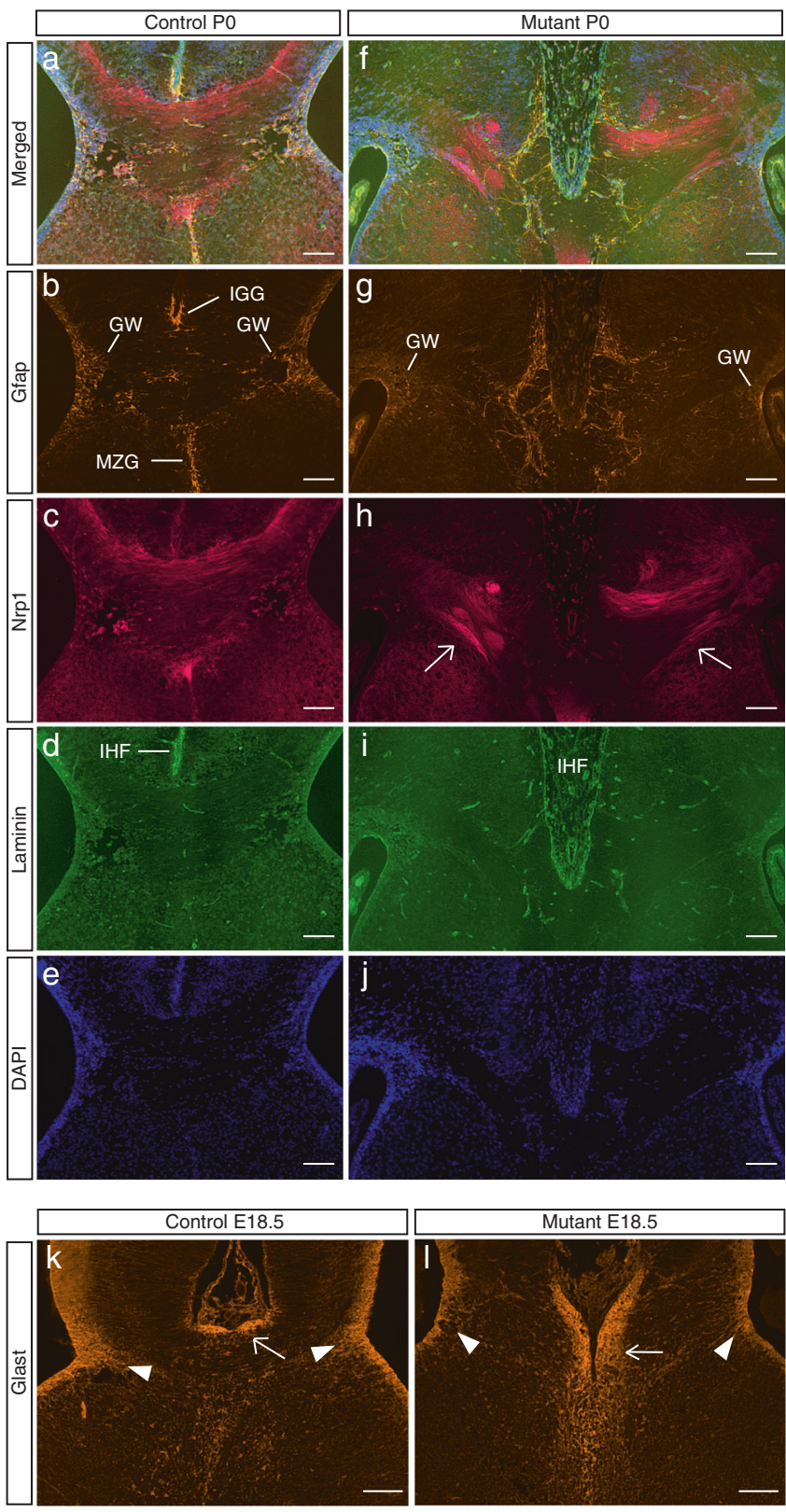

Fig. 3 Aberrant midline glia in mutant mice. a-j Immunostainings of PO coronal brain sections: Neuropilin 1-positive cortical axons fail to cross horizontally in mutant animals. Instead, some axon bundles deviate ventrally at the ipsilateral side (arrows in $\mathbf{h}$ ). Gfap-positive midline glia are aberrantly positioned and the glial wedge population is diminished in the mutant brain (g) GW glial wedge, IGG indusium griseum glia, MZG midline zipper glia. A widened interhemispheric fissure (IHF, laminin-positive connective tissue cells and basement membranes are stained in $\mathbf{d}$ and $\mathbf{i}$ ) that is not crossed by cortical axons is present in the mutant brain. $\mathbf{k}$, I Immunostainings of E18.5 coronal brain sections with an anti-Glast antibody (red immunosignals). The Glast-positive radial glial population at the position of the prospective Gfappositive GW is reduced and shows shorter radial processes (arrowheads in k, I). Glast-positive immunosignals above the developing corpus callosum are horizontally positioned in the control brain (arrow in $\mathbf{k}$ ) but deviate toward the midline in the mutant brain (arrow in I). All scale bars: $100 \mu \mathrm{m}$

which instead deviated ventrally (Fig. 3h). Gfap-positive glia cells surrounded the fissure in the mutant brain (Fig. 3g) but did not concentrate at the fissure base and along the midline below the $\mathrm{CC}$, and thus did not form distinct IGG and MZG regions as in the control brain (compare Fig. 3b to Fig. 3g). In addition, a reduced Gfap-positive cell population was found at the GW position (Fig. 3g). Interestingly, Glast-positive RGCs, which give rise to Gfap-positive guidepost cells, were already mispositioned at E18.5 (Fig. 3k, l). Furthermore, at the GW position, the area of Glast-positive RGCs and their processes was reduced in the mutant brain (Fig. 3k, l).

Thus the failed midline crossing of commissural axons in mutant mice is associated with an aberrant arrangement of Gfappositive IGG and MZG guidepost cells and Glast-positive midline radial glial precursor cells at these positions, a paucity of the mature Gfap-positive and the precursor Glast-positive GW populations, and a widening of the interhemispheric fissure.

The RGC population is diminished in mutant mice. Nissl stainings of postnatal forebrain sections showed reduced neuronal cell numbers in mutants, which explains the microcephaly (Supplementary Fig. 4b). This finding and the reduced GW population in these animals led us to investigate the number of RGCs and intermediate progenitors, the precursors of neurons and astrocytes in the brain.

Immunostainings of the RGC population in the ventricular zone (Sox2-positive), the intermediate progenitor population in the subventricular zone (Tbr2-positive), and early born (Ctip2positive) cortical neurons were performed on E14.5 brain sections (Fig. 4a). All three layers were significantly thinned (Fig. 4b), but their cell density was not different (Fig. 4c), indicating that cell numbers of these populations are reduced in the mutant brains. RGCs can be cultured as neurospheres ${ }^{29}$, and we found a dramatically decreased neurosphere-forming capacity in cultures from E15.5 mutant brain tissue (Fig. 4d).

Taken together, these data indicate that RGC maintenance is impaired in the mutants, resulting in a reduced number of these cells and their progeny, and thus leading to microcephaly.

Reduced Hes 5 expression at the developing GW position. The transcription regulator and Notch effector Hes5 is a key factor for RGC maintenance and promotion of astrocyte development in mice $^{30}$. Interestingly, Notch signaling promotes midline glial cell fates in Drosophila ${ }^{31}$ and Smarcb1 binds to Hes1 and Hes5 promoters in mouse myoblasts ${ }^{32}$. We investigated the expression of these genes in embryonic brains at the level of developing CC. In situ hybridization experiments did not reveal an obvious difference in Hes 1 expression between control and mutant brains. Interestingly, a distinct Hes 5 pattern was found in the medial walls of the lateral ventricles: in controls, a ventral domain of stronger Hes 5 expression sharply abutted a domain of weaker expression dorsally (Fig. 4e). The border between these low and high Hes5 expression fields was located at the region where GW RGCs are generated (Fig. 4e). In mutants, the difference between the dorsal and ventral Hes5 expression was diminished and the expression levels in the ventral region were lower compared with control brains (Fig. 4e).

To conclude, decreased Glast-positive radial glial and Gfappositive GW cell numbers in the mutant brain are accompanied by reduced Hes 5 expression at the developing GW site. Given the known role of Hes 5 in RGC maintenance and in the promotion of astrocyte formation, our results suggest that diminished Hes5 activation contributes to these GW defects.

Increased CP tissue in Smarcb1 mutant mice. Increased CP tissue, most strikingly in the lateral ventricles, and also evident in the third ventricle, was another remarkable dorsal forebrain midline alteration in Smarcb1 mutants (Fig. 5a).

To assess CP development, we performed in situ hybridizations with an antisense probe for Transthyretin (Ttr), a marker for CP 

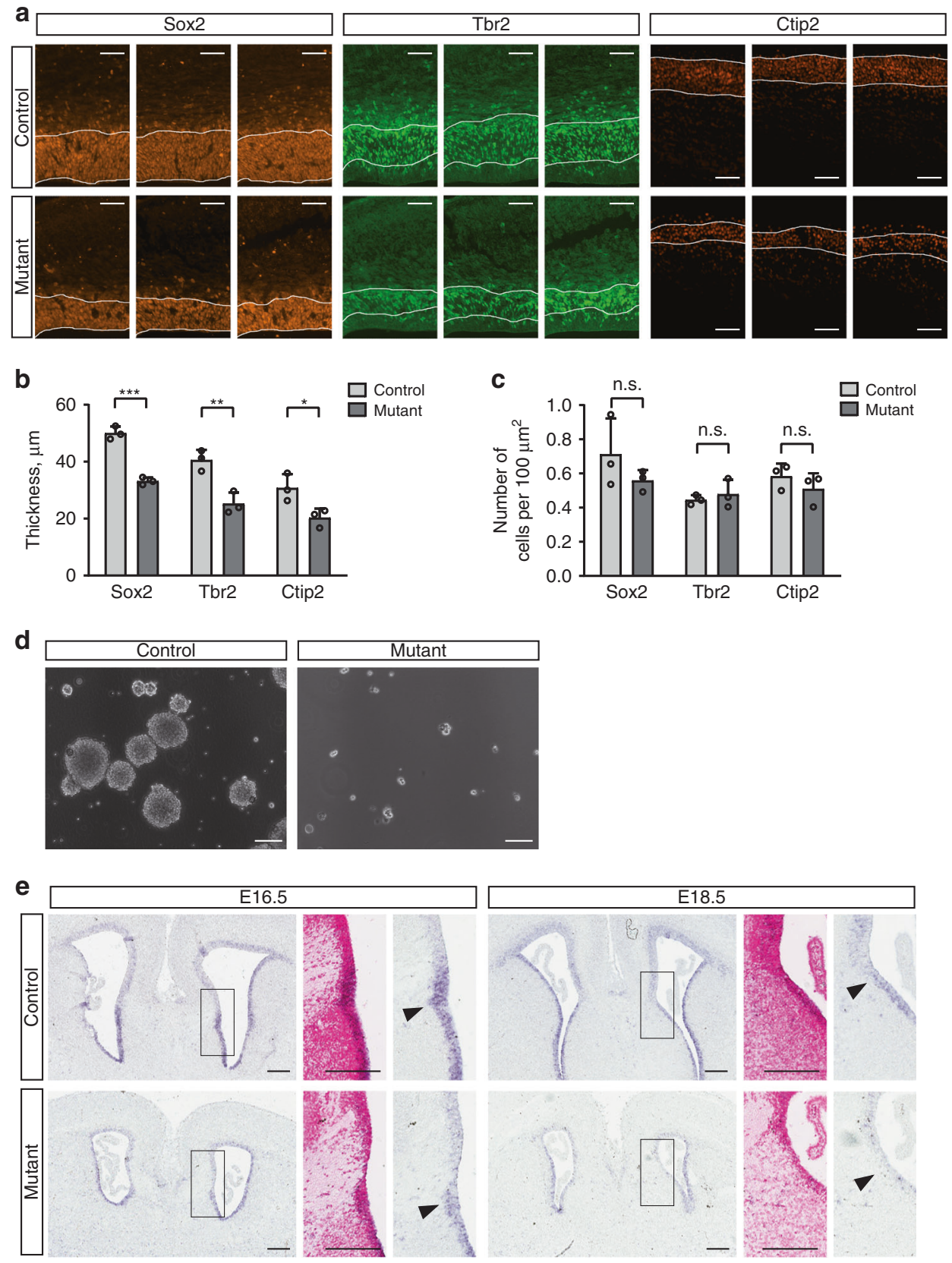

Fig. 4 Reduced neural stem and progenitor cells in the embryonic mutant brain. a Immunostainings of coronal forebrain sections from three mutant and three littermate control embryos at stage E14.5. b The thickness of the Sox2-, Tbr2-, and Ctip2-positive cortex layers is significantly reduced in the mutant compared to control animals. All bars display the mean with standard deviations. ${ }^{\star} p \leq 0.05,{ }^{\star \star} p \leq 0.01,{ }^{\star \star \star} p \leq 0.001$ (unpaired two-tailed Student's $t$ test). c Cell densities within the Sox2-, Tbr2-, and Ctip2-positive layers of the mutant compared with the control cortex. $p$ values (unpaired two-tailed Student's $t$ test): n.s. not significant. d Cells isolated from the mutant forebrain of E15.5 embryos fail to form large neurospheres in comparison with cultures established from E15.5 control brain tissue. Cultures of passage one (3 days after passaging) are shown. e Hes5 expression in coronal brains sections from E16.5 and E18.5 mutant and control animals detected by in situ hybridization (blue signals). Enlarged regions (framed areas) include the site of glial wedge development (arrowheads). Nuclear fast red stainings were performed to visualize the region of corpus callosum development, which appears white due to the paucity of nuclei. Scale bars: $100 \mu \mathrm{m}(\mathbf{a}, \mathbf{d}), 200 \mu \mathrm{m}(\mathbf{e})$. Source data are provided as a Source Data file

epithelium (Fig. 5a, b). These experiments revealed no alteration in early telencephalic CP field specification in the mutants but an increased lateral and third ventricle CP tissue mass from E16.5.

Next, we investigated CP tissue growth. In mutants and controls, cells producing Ki67, a protein present during all cell cycle phases but absent in $\mathrm{G}_{0}$, were found in the proximal part of the lateral ventricle CP epithelium at E14.5 and P0 (Fig. 5c). The presence of dividing cells at this position, i.e., near the root of the $\mathrm{CP}$, is in accordance with ref. ${ }^{33}$. In 4 -week-old mutants and controls, no Ki67-positive epithelial CP cells were present any longer. The number of dividing epithelial cells was not significantly higher in the proximal part of the lateral ventricle $\mathrm{CP}$ in E14.5 and P0 mutant animals (Fig. 5d). However, the number of $\mathrm{CP}$ branches was increased in the mutant lateral ventricle at P0 (Fig. 5c, e), which can also be seen on Ttr in situ hybridization sections (lowest panels in Fig. 5a).

In summary, mutant mice exhibited CP enlargement in the lateral and third ventricles, which seems to be due to increased 


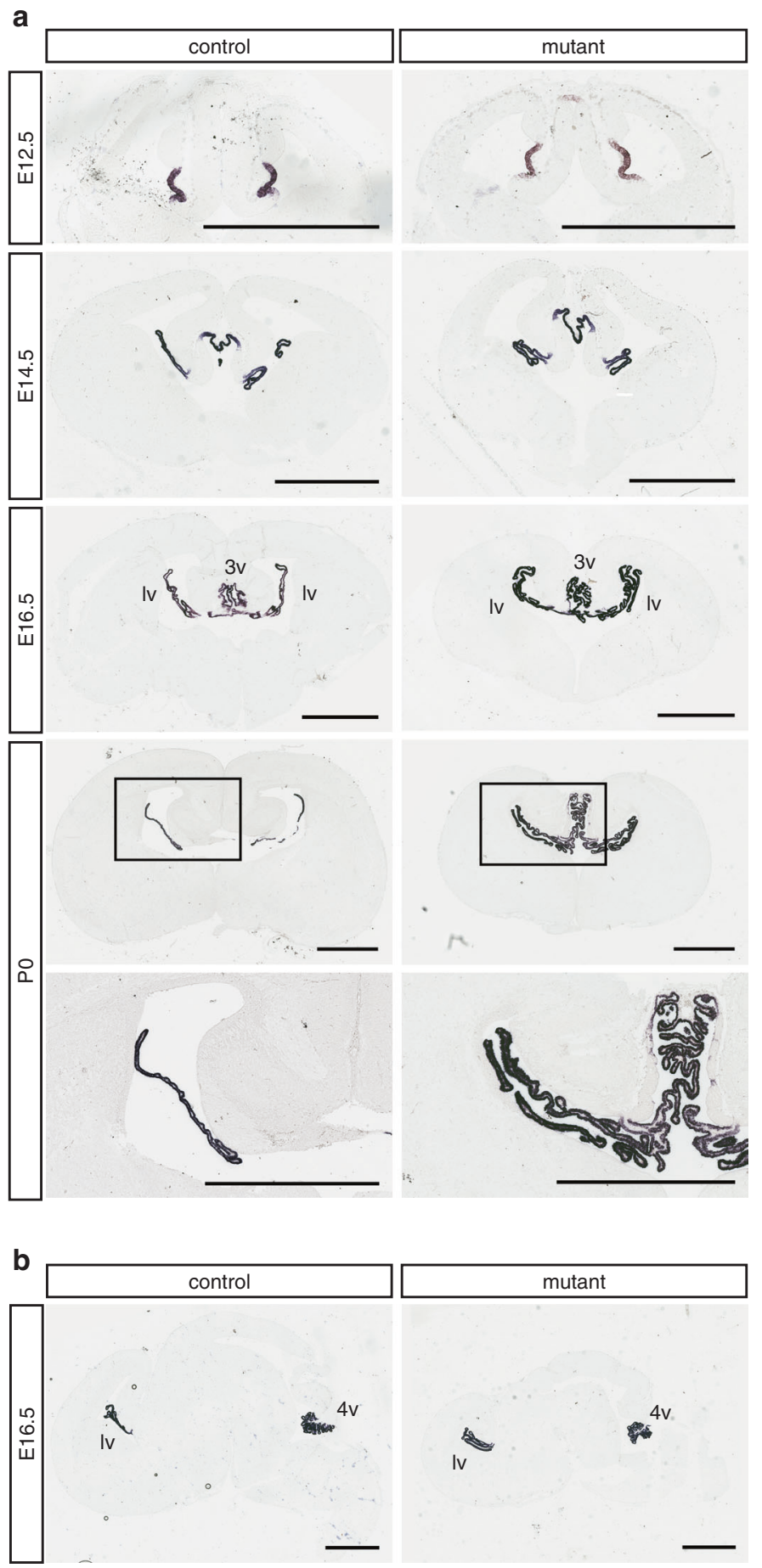

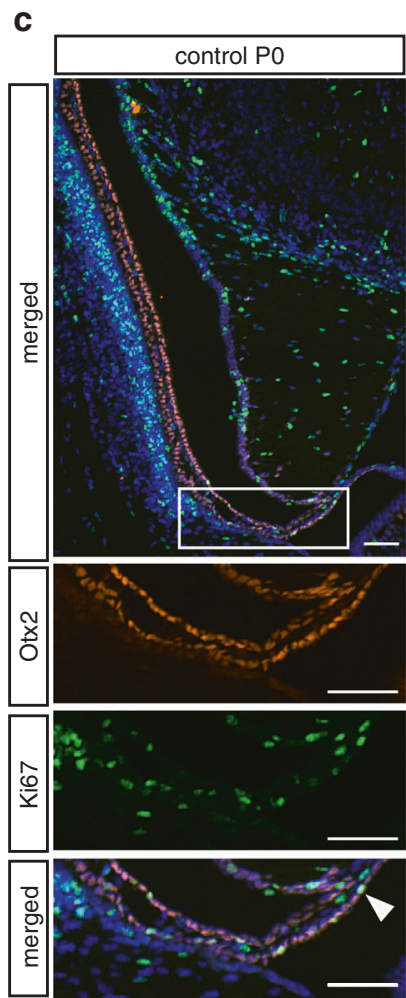

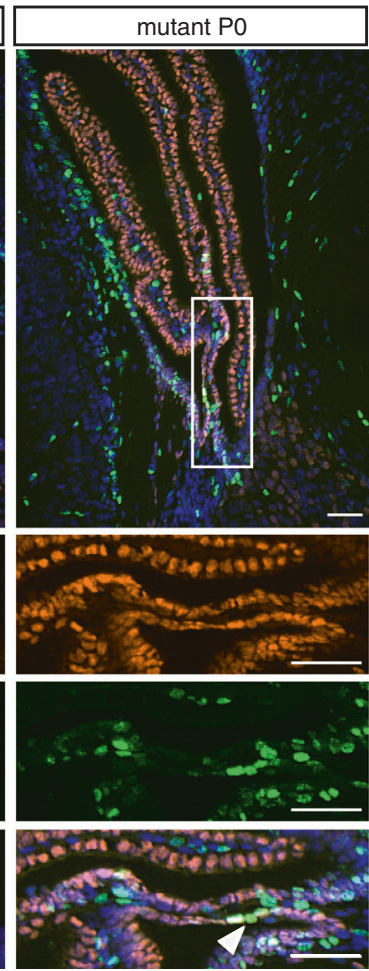

d

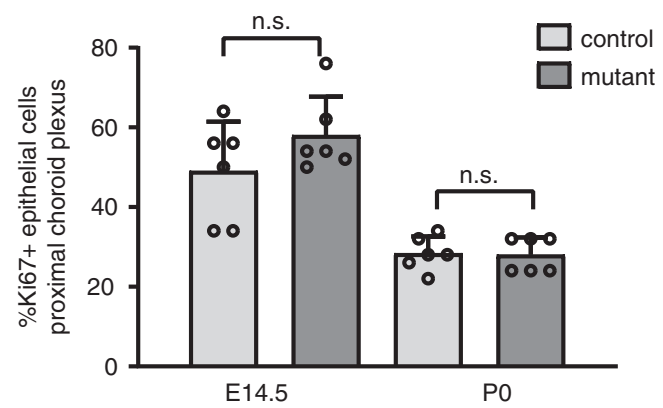

e

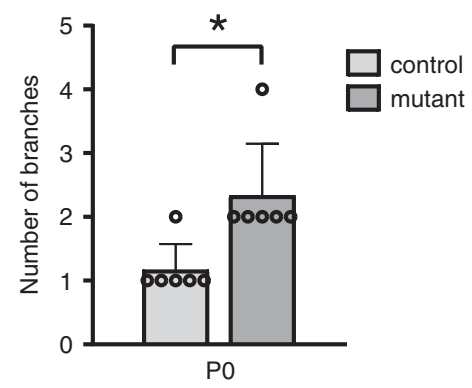

Fig. 5 Mutant mice develop a larger mass of Ttr-expressing choroid plexus (CP). a, b Ttr expression detected by in situ hybridizations. a Coronal brain sections at the level of the lateral to third ventricle junction from different developmental stages. Note the increased number of CP tissue folds in the lateral and third ventricles of the PO mutant brains. Enlarged regions of PO sections are shown at the bottom. b Sagittal sections from E16.5 animals. Scale bars (a, b): $1 \mathrm{~mm}$. c Immunostainings of PO coronal brain sections containing the site of CP attachment to the ventricle wall (proximal CP). Otx2-positive CP epithelial cells (red), Ki67-positive cells (green), and DAPI-positive nuclei (blue) are shown. Lower panels display higher magnifications of the proximal CP region framed in the upper panel. Arrowheads point to Ki67-positive CP epithelial cells. Scale bars: $100 \mu$ m. d Percentage of Ki67-positive cells present in the proximal Otx2-positive CP tissue determined in E14.5 and PO animals. The most proximal 50 cells starting from the attachment point of the CP were analyzed. The right and the left lateral ventricle of three control and three mutant animals of the same litter were investigated (six choroid plexi per group). Bars display the mean with standard deviations. $p$ values (unpaired two-tailed Student's $t$ test): n.s. not significant. e Number of branches in CP tissue of PO animals. The right and the left lateral ventricle of three control and three mutant animals of the same litter were investigated (six choroid plexi per group). Bars display the mean with standard deviations. $p$ values (unpaired two-tailed Student's $t$ test): ${ }^{\star} p \leq 0.05$. Source data are provided as a Source Data file 
branching of this tissue. Based on histological criteria (intact papillary architecture, no nuclear pleomorphisms, no necrosis, no increased proliferation at postnatal stages), we classify the enlarged $\mathrm{CP}$ tissue as benign lesion. Considering human $\mathrm{CP}$ pathologies, these alterations resemble diffuse villous hyperplasia or bilateral CP papilloma (the latter is World Health Organization (WHO) grade I). It is currently unresolved if these are two distinct entities and no clear diagnostic criteria exist to distinguish them ${ }^{34}$.

Smarcb1 mRNA levels in embryonic Smarcb1 ${ }^{+/-}$brain tissue. In contrast to Smarcb1 mutant mice described here, no abnormalities in terms of body size, head size, or brain anatomy have been reported for heterozygous conventional Smarcb1 knockout mice $\left(S m a r c b 1^{+-}\right)$generated by three different groups ${ }^{13,35,36}$. The only phenotype ascribed to these animals are soft tissue tumors, mainly sarcomas, that are thought to develop upon additional loss-of-function of the second Smarcb1 allele.

To better understand why a complete inactivation of one Smarcb1 allele, which takes place in all cells from the zygote stage on $\left(S m a r c b 1^{+/-}\right)$, does not lead to the phenotype seen in Smarcb1 ${ }^{+/ i n v} \mathrm{NesCre}^{+/-}$mice, we investigated heterozygous Smarcb1 $1^{+/}$animals generated by ref. ${ }^{13}$ (Supplementary Fig. 5). Brains from nine investigated postnatal Smarcb1 ${ }^{+/-}$mice were macroscopically indistinguishable from their Smarcb1 ${ }^{+/+}$littermates and sections of six analyzed animals did not reveal any brain midline defects (Supplementary Fig. 5c). In contrast to reduced transcript levels in E14.5 forebrain tissue from Smarcb1 mutant animals, quantitative reverse transcriptase-polymerase chain reaction (qRT-PCR) analyses revealed no significant difference in Smarcb1 transcript abundance between Smarcb1 $1^{+/}$and Smarcb1 $1^{+/+}$littermates, also in case of primers that should only amplify a sequence from the wild-type allele in Smarcb1 $1^{+/}$tissue (Supplementary Fig. 5d). Thus the lack of a neurodevelopmental phenotype in Smarcb1 $1^{+/-}$animals can be explained by unaltered Smarcb1 transcript levels, which are due to a compensatory upregulation of Smarcb1 gene expression from the second wild-type allele. This mechanism has been analyzed in embryonic fibroblasts from these mice ${ }^{37}$.

\section{Discussion}

In comparison to other transgenic mice with midline glia aberrations, several aspects of the Smarcb1 mutant animals are unique, indicating that the molecular consequences of reduced Smarcb1 levels are not identical to the genetic alterations in other models. To our knowledge, a large forebrain midline cleft, as seen in the severely affected Smarcb1 mutants, has not been found in any other published model with midline glia aberrations and/or forebrain commissural defects, nor do other mouse models display additional midline defects seen in Smarcb1 mutant mice, namely, increased CP tissue and cerebellar midline aberrations. For example, transgenic mice with a conditional inactivation of Lhx2 in cortical RGCs (Cre expressed under Emx1 or Nestin promoter elements) lack the hippocampal commissure and CC and show a prominent cleft between the cerebral hemispheres ${ }^{38}$. In contrast to Smarcb1 mutants, however, this cleft does not further extend ventrally and all animals possess an anterior commissure. Interestingly, the CC defect in Lhx2 mutants is thought to be caused by a reduced to absent GW due to abnormal radial GW precursors, a feature similar to the Smarcb1 mutant mice. Animals lacking transcription factors Nfia or Nfib are characterized by a failure of precursor cells to mature to Gfappositive midline astroglia $24,39-42$. In Smarcb1 mutant mice, however, Gfap-positive midline glia are present, but their localization is disturbed and the GW population is diminished. The defect in homozygous Nfia or Nfib knockout mice is accompanied by an abnormal retention of the interhemispheric fissure. This fissure is, however, much thinner and does not result in a cleft as in Smarcb1 mutants ${ }^{24}$. Smarcb1 is a component of chromatin remodeling complexes that modulate chromatin state and DNA accessibility to transcriptional regulators, thereby influencing gene expression patterns. In the present study, we identified reduced Hes 5 transcript levels at the site of GW development, and it will be important to find out if the various abnormalities in different brain regions of Smarcb1 mutant mice are all caused by the same or different downstream consequences of reduced Smarcb1 levels in RGCs.

Although single clinical reports on structural brain abnormalities in CSS exist, a thorough and comparative analysis of brain midline defects has not been published, and the developmental basis of these defects is unknown.

We have generated the first Smarcb1 mutant mouse model that shows features of SMARCB1-CSS and SMARCB1-related ID-CPH and exhibits a benign lesion of increased tissue mass (CP hyperplasia/papilloma) (Table 2). These mutant mice have striking brain midline defects affecting (i) the telencephalon (lack of the hippocampal commissure, partial or complete lack of the $\mathrm{CC}$ and the anterior commissure, disturbed fusion of cerebral hemispheres, and increased lateral ventricle CP tissue), (ii) the diencephalon (disturbed fusion of thalamic halves, increased third ventricle $\mathrm{CP}$ ), and (iii) the cerebellum (fusion of the cerebellar hemispheres and hypoplastic vermis-like structure). Interestingly, a brain midline defect, namely, decreased CC volume, is also present in animals with a heterozygous loss-of-function mutation in another CSS-causing gene, Arid $1 b^{43}$.

Table 2 Comparison of mutant mice with SMARCB1-related CSS and ID-CPH

\begin{tabular}{|c|c|c|c|}
\hline & $\begin{array}{l}\text { CSS patients with proven } \\
\text { SMARCB1 mutations }\end{array}$ & $\begin{array}{l}\text { ID-CPH patients with a distinct } \\
\text { SMARCB1 mutation }\end{array}$ & $\begin{array}{l}\text { Mutant mice } \\
\text { (Smarcb1 }^{+/ \text {inv }} \mathrm{NesCre}^{+/-} \text {) }\end{array}$ \\
\hline $\begin{array}{l}\text { Microcephaly (in patients: reduced occipitofrontal } \\
\text { circumference) }\end{array}$ & $(15 / 15) 100 \%$ & $(0 / 4) 0 \%$ & $100 \%$ \\
\hline Agenesis or hypoplasia of the corpus callosum & $(14 / 15) 93 \%$ & (4/4) $100 \%$ & $94 \%$ \\
\hline Cerebellar hypoplasia & $(2 / 15) 13 \%$ & $(2 / 4) 50 \%$ & $100 \%$ \\
\hline $\begin{array}{l}\text { Cerebellar midline abnormality (in patients: } \\
\text { Dandy-Walker malformation or variant, vermis } \\
\text { hypoplasia) }\end{array}$ & (4/15) $27 \%$ & Reduced vermis size (2/4) 50\% & $95 \%$ \\
\hline Choroid plexus hyperplasia & Not reported/found & (4/4) $100 \%$ & $100 \%$ \\
\hline Growth impairment & $(16 / 16) 100 \%$ & $\begin{array}{l}\text { Intrauterine growth retardation } \\
(1 / 4) 25 \%\end{array}$ & $100 \%$ \\
\hline
\end{tabular}


We identified similar midline defects, reduced to absent telencephalic commissures, hypoplastic, or absent septum pellucidum, and increased lateral ventricle CP tissue, in 9 of the 11 CSS patients (5 with SMARCB1 mutations, 1 with a SMARCE1 mutation, and 3 with $A R I D 1 B$ mutations), although not all of these defects were present in every patient. A cerebellar midline abnormality was found in three cases: mild vermis hypoplasia in an individual with a SMARCB1 mutation, and a Dandy-Walker variant in two individuals, one with a SMARCE1 mutation and one with a SMARCB1 mutation. Developmental cerebellar defects defined as the Dandy-Walker syndrome are classified into three categories (variant, malformation, Mega cisterna magna), all of which can occur in CSS. The variant is characterized by a hypoplastic cerebellar vermis and a mild enlargement of the fourth ventricle and posterior fossa. The cerebellar midline defect in mutant mice includes hypoplasia of a vermis-like structure and fusion of the cerebellar hemispheres. The former is a feature of the Dandy-Walker spectrum, the latter is reminiscent of rhombencephalosynapsis, which is also associated with partial or complete vermis agenesis; rhombencephalosynapsis itself has so far not been reported in CSS.

The brain midline defects in these nine patients have so far not been recognized as a characteristic feature of CSS. This might be due to different reasons: (i) brain MRIs are not always performed, (ii) only very obvious aberrations such as CC agenesis are typically diagnosed, and (iii) the Dandy-Walker syndrome phenotypes are less frequent in CSS. Moreover, CC and cerebellar alterations were not seen as potentially associated with each other. Kosho et al. found that, among CSS patients with analyzed structural brain abnormalities, the majority had CC agenesis (eight of nine with SMARCB1, six of seven with SMARCA4, one of two with SMARCE1, and seven of eight with ARID1A mutations) ${ }^{17}$. Moreover, a Dandy-Walker malformation was present in one of nine (SMARCB1), two of seven (SMARCA4), one of two (SMARCE1) and one of eight (ARID1A) cases $^{17}$. A survey on CSS and ID individuals with pathogenic $A R I D 1 B$ variants revealed a high frequency of complete CC agenesis (29\% in ARID1B-CSS and $28.2 \%$ in ARID1B-ID) and hypoplasia/partial CC agenesis (17.7\% in ARID1B-CSS and 7.7\% in ARID1B-ID) ${ }^{44}$. A thin CC is also present in all four reported patients with $S M A R C B 1$-related ID-CPH ${ }^{11}$. In two of these, a reduced vermis size was found.

It is currently not understood how alterations in genes encoding BAF complex components can lead to clinical outcomes that were so far recognized as distinct disease entities: tumor development or ID/neurodevelopmental disorders ${ }^{3}$.

SMARCB1 mutations in CSS are germline de novo heterozygous non-truncating missense mutations or small in-frame deletions within exons 8 and $9^{6,7,9}$. Patients with SMARCB1related ID-CPH carry a de novo germline missense mutation in exon 2 (c.110G $>$ A;p.Arg37His) ${ }^{11}$. The effect of these mutations on the function of the SMARCB1 protein remains unknown. SMARCB1 heterozygous germline mutations underlying tumor predisposition syndromes, the rhabdoid tumor predisposition syndrome 1 (RTPS1) and schwannomatosis, are in the vast majority of a different type. RTPS1 patients carry germline heterozygous truncating loss-of-function mutations or large deletions, and somatic loss of heterozygosity leads to malignant intracranial and extracranial rhabdoid tumors as well as other malignancies such as CP carcinomas, medulloblastomas, and central primitive neuroectodermal tumors ${ }^{45}$. No SMARCB1 protein is typically detectable in these tumor tissues. In contrast, the other SMARCB1 tumor predisposition syndrome, schwannomatosis, is typically caused by heterozygous non-truncating germline SMARCB1 mutations that mostly occur in exons 1,2 or in the $3^{\prime}$-untranslated region $\left(3^{\prime} \mathrm{UTR}\right)^{46,47}$. Affected patients develop benign tumors, nerve sheath tumors (schwannomas), and meningiomas. Frequent loss of the second allele in combination with biallelic loss of NF2 has been reported in such tumor tissues, indicating that SMARCB1 acts as a tumor suppressor in schwannomas and that the familial SMARCB1 mutations lead to a loss-of-function. Analyses of such mutations suggest that they do not result in a complete loss of the protein as in rhabdoid tumors but in reduced SMARCB1 gene expression ${ }^{46,47}$. The occurrence of either malignant rhabdoid tumors or schwannomatosis in families with germline SMARCB1 mutations ${ }^{48,49}$ and the occurrence of schwannomatosis in a patient that survived a malignant rhabdoid tumor ${ }^{50}$ support the idea that mutations in both RTPS1 and schwannomatosis are loss-of-function mutations of different severity but with an overlapping phenotypic spectrum.

To date, a single CSS individual with a germline missense SMARCB1 mutation has been reported to suffer from a SMARCB1-related tumor entity, namely schwannomatosis, a benign tumor disease $\mathrm{s}^{51}$. In this patient with a SMARCB1 mutation in exon 9, inactivation of the second allele had occurred in the tumor tissue. Strikingly, the co-occurrence of ID and a benign overgrowth lesion (CP papilloma/hyperplasia) is described in four unrelated individuals with a recurrent germline missense mutation in SMARCB1 exon 2 (SMARCB1-related ID-CPH) ${ }^{11}$. These patients show some overlap with CSS individuals (brain midline abnormalities, severe ID, congenital heart defects, kidney abnormalities, and feeding difficulties) but lack other features that are typical for SMARCB1-CSS (impaired growth, microcephaly, fifth finger anomalies, scoliosis, and epilepsy) (Table 2).

SMARCB1 mutations occur in a substantial proportion of $\mathrm{CP}$ tumors ${ }^{52-56}$. The majority are carcinomas (WHO grade III) and show SMARCB1 mutations that are predicted to result in a truncated protein. It remains unclear whether some or potentially all of the SMARCB1-mutated malignant CP tumors (carcinomas) represent a separate entity or are misdiagnosed atypical teratoid/ rhabdoid tumors ${ }^{52,57}$. SMARCB1 mutations have been found in two CP papilloma ${ }^{58}$ and two atypical CP papilloma (WHO grade II) cases $^{53,58}$. The papillomas and one atypical papilloma tumor are possibly due to homozygous deletions encompassing exon $9^{58}$; an acquired homozygous deletion including exon 4 was found in the other atypical papilloma ${ }^{53}$.

The Smarcb1 mutant mouse model combines features of both neurodevelopmental defects and a benign lesion of increased tissue mass (CP hyperplasia/papilloma). Several abnormalities found in four individuals with SMARCB1-related ID-CPH ${ }^{11}$ are recapitulated by this model (Table 2): CP enlargement in both lateral ventricles that occurs early during development (diagnosed prenatally or early postnatally in patients), CC abnormalities (thinned in all four cases), and reduced cerebellar vermis (mild atrophy in one case and small size in another case). However, microcephaly and growth impairment, two features typically associated with SMARCB1-CSS and present in all Smarcb1 mutant mice, are not characteristic for these four patients.

The genetic alteration in Smarcb1 mutant animals (monoallelic reversible disruption of exon 1 in Nestin-expressing cells), and the fact that Smarcb1 mRNA levels were reduced by about $30 \%$ in embryonic brain tissue, indicate that this phenotype is due to a partial loss-of-function. Notably, Smarcb1 mRNA levels were unaltered in embryonic brain tissue from Smarcb1 ${ }^{+/-}$mice, which permanently lack one allele and do not show obvious brain abnormalities. A potential mechanism underlying the compensatory increase of transcripts from the wild-type allele in these mice is a negative autoregulation of the SMARCB1 gene. Moreover, the permanent monoallelic inactivation of Smarcb1 in Nestin-expressing cells in a mouse model with Smarcb1 exon 1 flanked by loxP sites of identical orientation (Smarcb1 $\left.1^{+/ f l o x} \mathrm{NeSCr}^{+/-}\right)$does not lead to an apparently aberrant brain phenotype either ${ }^{59}$. These results suggest that the complete monoallelic Smarcb1 inactivation 
in Smarcb1 $1^{+/-}$and Smarcb1 $1^{+/ f l o x} \mathrm{NesCre}{ }^{+/-}$mice can be fully compensated by an increased expression from the wild-type allele, whereas the cellular compensatory mechanisms do not suffice to counterbalance the effect of the continuous exon 1 inversion in Smarcb1 $1^{+/ i n v} \mathrm{NesCre}{ }^{+/-}$mice.

In light of our data and the above-mentioned findings, it is tempting to interpret the consequences of pathogenic germline SMARCB1 alterations according to three categories.

i. Monoallelic alterations resulting in a partial SMARCB1 lossof-function due to reduced Smarcb1 mRNA levels (as in our mouse model) or missense mutations leading to the generation of an altered SMARCB1 protein product (as in CSS and ID-CPH patients) cannot be fully compensated by the second intact allele and lead to ID/neurodevelopmental defects and to benign brain lesions (CP hyperplasia/ papilloma).

ii. Complete loss-of-function alterations in one allele (truncating mutations and large deletions) that lead to a complete lack of a protein product can be fully compensated through an increased expression from the second intact allele and do not lead to neurodevelopmental defects. However, they predispose to malignant tumors upon loss-of-function of the second allele.

iii. Germline monoallelic mutations predisposing to schwannomatosis (benign tumors) are typically non-truncating and include missense and nonsense mutations, splice site alterations, and mutations in the $3^{\prime}$ UTR. Such mutations have never been detected in CSS and some of them are predicted to lead to reduced SMARCB1 expression. The effect of these mutations could either be fully compensated or not suffice to cause a CSS/neurodevelopmental phenotype. Conversely, a CSS-causing mutation in SMARCB1 exon 9 can predispose to schwannomatosis. Moreover, rhabdoid tumor-predisposing mutations can also lead to schwannomatosis. In addition to the type of mutation, the developmental stage and thus the cell type in which two mutated alleles are present is another determinant of schwannoma versus rhabdoid tumor development ${ }^{60}$.

So far, it was not understood how mutations in SMARCB1 lead to any of the features of CSS and ID-CPH. Our data highlight a novel role of Smarcb1 in brain midline development, aspects of which can be explained by a reduced number and mispositioning of midline RGCs. Moreover, our results are of high clinical relevance. We suggest that bilateral $\mathrm{CP}$ hyperplasia/papilloma should be regarded as indicative for potential mutations in a CSScausing gene. Finally, we show that the spectrum of brain midline defects in CSS is broader than so far recognized, thereby providing novel, highly relevant classification criteria for CSS and related ID/neurodevelopmental disorders.

\begin{abstract}
Methods
Patients. Eleven patients with a molecularly confirmed diagnosis of CSS were reevaluated for brain malformations. Cranial MRI scans were systematically reviewed for structural brain abnormalities by a pediatric radiologist (J.S.). Patients 1, 7, and 10 were described previously ${ }^{9,18}$. Data on the other patients have not been published yet. Some cases were part of larger studies approved by local institutional review boards (ethical votum 12-5089-BO for CRANIRARE and 5590 for Chromatin-Net; ethics committee of Ärztekammer Hamburg, PV3802; ethics committee at the Warsaw Medical University). Written informed consent to publish patient data was obtained from all families of the index individuals. The study was performed according to the Declaration of Helsinki protocols.
\end{abstract}

Animals. Smarcb1 $1^{+/ i n v}$ mice, originally termed $S n f 5^{+/ i n v}$, were kindly provided by Charles W. Roberts (Children's Hospital Boston, Harvard Medical School, Boston, USA). We confirmed that the loxP sites surrounding Smarcb1 exon 1 are of opposite orientation by sequencing genomic DNA from these animals. $\mathrm{Nes} C \mathrm{Cr}^{+/-}$ mice were kindly provided by Günther Schütz (German Cancer Research Center,

Heidelberg, Germany). Smarcb1 $1^{+-}$mice were a kind gift from Stephen N. Jones (University of Massachusetts Medical School, Worcester, USA). Alleles were maintained on a C57BL/6N background. All animal procedures were approved by the local authorities (Regierungspräsidium Darmstadt, Hesse, Germany). To confirm developmental stages of mouse embryos, anatomical criteria were applied, including the morphology of the limb buds/limbs and the cephalic region.

Neurosphere culture. E15.5 forebrain tissue was minced and incubated with Accutase (PAA) for $15 \mathrm{~min}$ at $37^{\circ} \mathrm{C}$. The cell suspension was triturated with a pipet tip, passed through a $100 \mu \mathrm{m}$ cell strainer and centrifuged at $200 \times g$ for $3 \mathrm{~min}$. The pellet was resuspended in serum-free neurosphere proliferation medium (Dulbecco's modified Eagle's medium/F12 medium (Gibco) supplemented with B27 supplement (Gibco), $30 \mathrm{mM}$ HEPES (Gibco), $20 \mathrm{ng} / \mathrm{mL}$ epidermal growth factor (R\&D), and $20 \mathrm{ng} / \mathrm{mL}$ fibroblast growth factor (R\&D)). Six days after the primary tissue isolation, cells were passaged using Accutase and cultured in neurosphere proliferation medium at a density of $10^{5}$ cells $/ \mathrm{mL}$.

PCR using genomic DNA as template. Genomic DNA was isolated using the E.Z N.A. Tissue DNA Kit (OMEGA bio-tek, USA). Standard genotyping PCR conditions using ear tissue (final reaction volume of $25 \mu \mathrm{L}$, final primer concentrations $0.4 \mu \mathrm{M})$ were as follows. Primer sequences are listed below in Table 3 .

Smarcb $1^{\text {inv }}$ : Primers Snf5CE2251 and Snf5CER $2454 ; 95^{\circ} \mathrm{C} 5$ min, 25 cycles $\left(95^{\circ}\right.$ C $1 \mathrm{~min}, 66^{\circ} \mathrm{C} 1 \mathrm{~min}\left[-0.4^{\circ} \mathrm{C}\right.$ per cycle $\left.], 72^{\circ} \mathrm{C} 1 \mathrm{~min}\right), 20$ cycles $\left(95^{\circ} \mathrm{C} 1 \mathrm{~min}, 56^{\circ}\right.$ C $\left.1 \mathrm{~min}, 72^{\circ} \mathrm{C} 1 \mathrm{~min}\right), 72^{\circ} \mathrm{C} 10 \mathrm{~min}$.

NesCre: Primers Cre fw4, Cre rev4, Gabral fw, Gabra1 rev; $95^{\circ} \mathrm{C} 5$ min, 35 cycles $\left(95^{\circ} \mathrm{C} 30 \mathrm{~s}, 62^{\circ} \mathrm{C} 30 \mathrm{~s}, 72{ }^{\circ} \mathrm{C} 1 \mathrm{~min}\right), 72{ }^{\circ} \mathrm{C} 5 \mathrm{~min}$.

Smarcb1 $1^{-}$: Primers B-Geo fw2, B-Geo rev2, Gabral fw, Gabral rev; $95^{\circ} \mathrm{C} 5$ min, 35 cycles $\left(95^{\circ} \mathrm{C} 30 \mathrm{~s}, 59^{\circ} \mathrm{C} 30 \mathrm{~s}, 72^{\circ} \mathrm{C} 30\right.$ s), $72{ }^{\circ} \mathrm{C} 5$ min. Gabral primers served as internal positive control.

To determine Smarcb1 knockout alleles in brain tissue, the following reactions were performed. Smarcb1-: Primers B-Geo fw, B-Geo rev, Smarcb1 exon $7 \mathrm{fw}$, Smarcb1 exon $7 \mathrm{rev} ; 95^{\circ} \mathrm{C} 5 \mathrm{~min}, 35$ cycles $\left(95^{\circ} \mathrm{C} 30 \mathrm{~s}, 62^{\circ} \mathrm{C} 30 \mathrm{~s}, 72^{\circ} \mathrm{C} 30 \mathrm{~s}\right), 72^{\circ} \mathrm{C}$ 5 min. Smarcb1 $1^{\text {inv: }}$ Primers Smarcb1 A, Smarcbl B, Smarcb1 C; $95^{\circ} \mathrm{C} 5$ min, 35 cycles $\left(95^{\circ} \mathrm{C} 30 \mathrm{~s}, 58^{\circ} \mathrm{C} 30 \mathrm{~s}, 72^{\circ} \mathrm{C} 30 \mathrm{~s}\right), 72^{\circ} \mathrm{C} 10 \mathrm{~min}$.

Staining of tissue sections. Tissue was fixed in $4 \%$ formaldehyde/phosphatebuffered saline (PBS) overnight, embedded in paraffin, and $5 \mu \mathrm{m}$ sections were cut using a Jung RM2055 device (Leica Biosystems) and placed onto Thermo Scientific $^{\mathrm{m}}$ Polysine Adhesion slides. Prior to stainings, sections were deparaffinized and rehydrated. For Nissl stainings, sections were incubated in $0.5 \%$ cresyl violet in $133 \mathrm{mM}$ sodium acetate, $\mathrm{pH} 4.0$ for $10 \mathrm{~min}$ at room temperature (RT) and washed twice with the sodium acetate solution for $5 \mathrm{~min}$. Sections were washed with

\section{Table 3 List of primers}

\section{Name}

B-Geo fw

B-Geo rev

B-Geo fw2

B-Geo rev2

Cre fw4

Cre rev4

Gabra1 fw

Gabra1 rev

Smarcb1 A

Smarcb1 B

Smarcb1 C

Smarcb1 exon $1 \mathrm{fw}$

Smarcb1 exon 2 rev

Smarcb1 exon $3 \mathrm{fw}$

Smarcb1 exon 4 rev

Smarcb1 exon $5 \mathrm{fw}$

Smarcb1 exon 6 rev

Smarcb1 exon $7 \mathrm{fw}$

Smarcb1 exon 7 rev

Smarcb1 isoform $1 \mathrm{fw}$

Smarcb1 isoform $1 \mathrm{rev}$

Smarcb1 isoform $2 \mathrm{fw}$

Smarcb1 isoform 2 rev

Snf5CE2251

Snf5CER2454

Tbp fw1

Tbp rev1 $\mathbf{5}^{\prime}-\mathbf{3}^{\prime}$ sequence

CGGTATCGATAAGCTTGATGATCTG

CGCATCGTAACCGTGCATCTGC

TATCCGAACCATCCGCTGTG

GTGGCCTGATTCATTCCCCA

GGTTCGCAAGAACCTGATGG

GCCTTCTCTACACCTGCGG

AACACACACTGGAGGACTGGCTAGG

CAATGGTAGGCTCACTCTGGGAGATGATA

GAAAATCTAGAAAGCACAAATGAGAG

CAGGAAAATGGATGCAACTAAGAT

GCCACATAAACTGGGTGTAG

ATGGCGTTGAGCAAGACC

CATACGCAGGTAGTTTCCCAC

TGGATGGCAATGACGAGAAG

ATGCGGTTCCTGTTGATGG

CGAGACGCTTTTACCTGGAAC

GGGGTAGGACTCAATCTGCT

CTGAACATCCACGTGGGGAACATC

CTGAAGGCATAGGTCTTCTGGTGC

ACAAAACCTAACACTAAGGATCATG

CTTCTCGTCATTGCCATCCA

CTACATGATCGGCTCCGAG

TATCCATGATCATGTGACGATGC

CACCATGCCCCCACCTCCCCTACA

CAGGAAAATGGATGCAACTAAGAT

GGGAGAATCATGGACCAGAA

TTGCTGCTGCTGTCTTTGTT 
distilled water, dehydrated gradually in ethanol $(70 \%, 80 \%, 90 \%$, and $100 \%)$, and mounted in Entellan. For hematoxylin and eosin staining, slides were incubated in hematoxylin for 3-5 min, in tap water for $2 \mathrm{~min}$, stained with eosin $\mathrm{Y}$ for $4 \mathrm{~min}$, rinsed with water, dehydrated gradually in ethanol $(70 \%, 80 \%, 90 \%$, and $100 \%, 30 \mathrm{~s}$ each step), and mounted in Entellan. Images were acquired using an Aperio CS2 slide scanner (Leica Biosystems). For immunostainings, an epitope retrieval was performed by boiling sections in citrate buffer $(10 \mathrm{mM}$ Sodium citrate, $0.05 \%$ Tween-20, pH6.0) for $40 \mathrm{~min}$. After a permeabilization step (0.5\% Triton X-100/ PBS for $10 \mathrm{~min}$ ), primary antibodies were applied in $0.01 \%$ Triton X-100/PBS overnight at $4{ }^{\circ} \mathrm{C} .0 .01 \%$ Triton X-100/PBS only served as negative control. Sections were washed with PBS three times (10 min each) and incubated with secondary antibodies diluted in $0.01 \%$ Triton X-100/PBS at RT for $1 \mathrm{~h}$ followed by washing in PBS (10 min, two times). Specimens were then incubated in DAPI solution $(1 \mu \mathrm{g} / \mathrm{mL}$, Roche) for $10 \mathrm{~min}$, washed in PBS $(5 \mathrm{~min})$, rinsed briefly in water, dehydrated in ethanol, and air dried. For mounting, Fluorescence Mounting Medium (DAKO/Agilent) and coverslips (Thermo Scientific, Germany) were used. Immunofluorescent images were taken with a Zeiss Observer D1 or Zeiss Axiovert 200M microscope. The following primary antibodies were applied: Ctip2 (Abcam, ab18465, 1:500), Gfap (Dako, Z0334, 1:800), GLAST (Abcam, ab416-200, 1:100), Ki67 (Abcam, ab16667, 1:100), Laminin (Sigma, L9393, 1:400), Nrp1 (R\&D, AF566, 1:100), Otx2 (R\&D, AF1979, 1:1000), Satb2 (Abcam, ab69995, 1:200, kind gift from B. Schuetz, University of Marburg, Germany), SMARCB1 (CST, 91735, 1:500), Sox2 (Santa Cruz Biotechnology, sc-17320, 1:150), Tbr2 (Abcam, ab23345, 1:250). Secondary antibodies coupled to Cy3, AF488, and AF647 were from Dianova and diluted 1:300.

Quantitative RT-PCR. For cDNA synthesis, $1 \mu \mathrm{g}$ of total RNA (isolated using the AllPrep DNA/RNA Mini Kit, Qiagen) was incubated with $1 \mu \mathrm{L}$ random primers (500 ng/ $\mu \mathrm{L}$, Thermo Scientific) in a $12.5 \mu \mathrm{L}$ reaction volume at $65^{\circ} \mathrm{C}$ for $5 \mathrm{~min}$ followed by a short incubation on ice and reverse transcription at $42^{\circ} \mathrm{C}$ for $60 \mathrm{~min}$ upon addition of $200 \mathrm{U}$ M-MuLV reverse transcriptase (Thermo Scientific), $10 \mathrm{U}$ RNAsin (Thermo Scientific), $2 \mu \mathrm{L} 10 \mathrm{mM}$ dNTPs (Thermo Scientific) and $4 \mu \mathrm{L} 5 \mathrm{x}$ M-MLV reaction buffer Thermo Scientific) to a final reaction volume of $20 \mu \mathrm{L}$. StepOnePlus System (Applied Biosystems) and SYBR Green as fluorescent reporter were used for qRT-PCR measurements. Gene-specific PCR products were measured continuously, and the difference in the threshold number of cycles between the gene of interest and TATA-binding protein $(\mathrm{Tbp})$ was then normalized relative to the standard chosen for each experiment and converted into fold difference. Four $\mu \mathrm{L}$ of 1:100 diluted cDNA were used as template in a $25 \mu \mathrm{L}$ qPCR reaction with $12.5 \mu \mathrm{L}$ of Power Up SYBR Green Master Mix (Applied Biosystems) and $0.2 \mu \mathrm{M}$ of the respective primers. qPCR reaction conditions were as follows: $95^{\circ} \mathrm{C}$ $10 \mathrm{~min}, 40$ cycles $\left(95^{\circ} \mathrm{C} 15 \mathrm{~s}, 55^{\circ} \mathrm{C} 1 \mathrm{~min}\right)$. Primer combinations for Smarcbl exon 1-2 amplification were: Smarcb1 exon $1 \mathrm{fw}$ and Smarcb1 exon 2 rev; for Smarcb1 isoform 1: Smarcb1 isoform $1 \mathrm{fw}$ and Smarcb1 isoform $1 \mathrm{rev}$; for Smarcb1 isoform 2 amplification: Smarcb1 isoform $2 \mathrm{fw}$ and Smarcb1 isoform 2 rev; for Smarcb1 exon 3-4 amplification: primers Smarcb1 exon $3 \mathrm{fw}$ and Smarcbl exon 4 rev; for Smarcb1 exon 5-6 amplification, primers Smarcb1 exon 5 fw and Smarcb1 exon 6 rev. Tbp cDNA amplified with primers Tbp fwl and Tbp revl was used as an internal control to measure the relative expression quantity of the target genes. Primer sequences are listed in Table 3.

In situ hybridization. A plasmid containing rat Ttr cDNA was a kind gift from Shubha Tole (Tata Institute of Fundamental Research, India)/Wei Duan (Deakin University, Australia). Hes 1 and Hes 5 mouse cDNA plasmids were kind gifts from Achim Gossler (MHH Hannover, Germany). Five $\mu \mathrm{g}$ of linearized plasmid purified with DNA Clean \& Concentrator-5 (Zymo Research) were transcribed using a digoxigenin RNA labeling mix (Dig-11-UTP, Roche, \#11209256910; RTP Set, Roche, \#11277057001) and T3, Sp6 (Promega) or T7 RNA polymerase (Roche). Sense probes served as negative controls. Deparaffinized and rehydrated sections were incubated with $7 \mu \mathrm{g} / \mathrm{mL}$ proteinase $\mathrm{K} / \mathrm{TE}$ buffer at RT for $15 \mathrm{~min}$, refixed with $4 \%$ paraformaldehyde/PBS at RT for $20 \mathrm{~min}$, briefly rinsed in water, acetylated in $0.0025 \%$ acetic anhydride/ $0.1 \mathrm{M}$ triethanolamine for $10 \mathrm{~min}$, washed in PBS for 5 min, dehydrated in increasing concentrations of ethanol, and air-dried. After a prehybridization step, $2 \mathrm{~h}$ at $55^{\circ} \mathrm{C}$ in hybridization buffer, containing $50 \%$ deionized formamide, $10 \%$ dextran sulfate, $1 \mathrm{mg} / \mathrm{mL}$ yeast tRNA, $1 \times$ Denhardt's solution, 0.2 $\mathrm{M}$ sodium chloride, $0.01 \mathrm{M}$ Tris buffer (pH 7.5), $0.05 \mathrm{M}$ EDTA, $0.005 \mathrm{M} \mathrm{NaH}_{2}$ $\mathrm{PO}_{4} \times \mathrm{H}_{2} 0,0.005 \mathrm{M} \mathrm{Na}_{2} \mathrm{HPO}_{4} \times 2 \mathrm{H}_{2} 0$, slides were incubated in a humidified chamber with DIG-labeled RNA probes in hybridization buffer at $55^{\circ} \mathrm{C}$ overnight. After hybridization, sections were washed with Wash solution $(50 \%$ formamide, $0.15 \mathrm{M}$ sodium chloride, $0.015 \mathrm{M}$ sodium citrate and $0.1 \%$ Tween- $20, \mathrm{pH} 7.0$ ) two times, $1 \mathrm{~h}$ each at $65^{\circ} \mathrm{C}$, followed by two washes with MABT $(0.1 \mathrm{M}$ maleic acid, $0.15 \mathrm{M} \mathrm{NaCl}$, and $0.1 \%$ Tween-20), $1 \mathrm{~h}$ each at RT. Washed slides were treated with blocking solution (20\% Normal Goat Serum in MABT), incubated with alkaline phosphatase-coupled anti-DIG antibody in blocking solution overnight, and extensively washed in MABT and TNMT $(0.1 \mathrm{M}$ Tris- $\mathrm{HCl}, \mathrm{pH} 9.5,0.1 \mathrm{M} \mathrm{NaCl}, 50$ $\mathrm{mM} \mathrm{MgCl} 2$ and $0.1 \%$ Tween-20.) The color reaction was started by adding NBT and BCIP in TNMT buffer with $5 \mathrm{mM}$ levamisole. The reaction was performed in the dark under coverslips at RT and stopped by washing in PBST. After washing and dehydrating, the sections were mounted in Kaiser's Glyceringelatine (Merck, Darmstadt, Germany). For consecutive nuclear fast red staining, the slides were incubated in $0.1 \%$ nuclear fast red (Merck, Darmstadt, Germany) for 2 min, rinsed with water, dehydrated, and mounted in Kaiser's Glyceringelatine (Merck,

Darmstadt, Germany). Images were acquired using an Aperio CS2 slide scanner (Leica Biosystems).

Image analysis. A cortical region above the lateral ventricle (three mutant and three littermate control E14.5 embryos were included) was selected with one border defined by the dorsomedial corner of the lateral ventricle. The width of the analyzed area along the lateral ventricle surface was $384 \mu \mathrm{m}$. The thickness of Sox2-, Tbr2-, and Ctip2-positive layers was calculated as an average of three measurements at 0,192 , and $384 \mu \mathrm{m}$. To determine the cell density within the three layers, cells expressing Sox2, Tbr2, or Ctip2 were manually counted using CellCounter plugin of the ImageJ software (https://imagej.nih.gov/ij/, National Institutes of Health, Bethesda, MD, USA). Double-positive $\left(\mathrm{Sox}^{+}{ }^{+} \mathrm{Tbr} 2^{+}\right)$cells were excluded from counting. The cell density was determined as the number of single Sox2-, Tbr2-, or Ctip2-positive cells within the respective layer divided by the area of the layer. The data were expressed as the number of cells $/ 100 \mu \mathrm{m}^{2}$.

Statistical analysis. GraphPad Prism (GraphPad software San Diego, CA) was used for graphical display. Statistical tests were performed with GraphPadPrism and Excel 2010 (Microsoft, USA). The Shapiro-Wilk test was used to test the normal distribution of data within groups. Student's $t$ tests (two-tailed, unpaired) were applied to determine if datasets are significantly different. n.s. not significant $(p>0.05),{ }^{*} p \leq 0.05,{ }^{* *} p \leq 0.01,{ }^{* *} p \leq 0.001$. Measurements were taken from distinct samples. Bars display the mean with standard deviations.

Reporting summary. Further information on research design is available in the Nature Research Reporting Summary linked to this article.

\section{Data availability}

The authors declare that all data supporting the findings of this study are available within the article and its supplementary information files or from the corresponding author upon reasonable request. The source data underlying Figs. 1f, g, 4b, c, and 5d, e and Supplementary Figs. 1a-e and 5a, d are provided as Source Data.

Received: 17 January 2019 Accepted: 5 June 2019

Published online: 04 July 2019

\section{References}

1. Kadoch, C. \& Crabtree, G. R. Mammalian SWI/SNF chromatin remodeling complexes and cancer: mechanistic insights gained from human genomics. Sci. Adv. 1, e1500447 (2015)

2. Masliah-Planchon, J., Bieche, I., Guinebretiere, J. M., Bourdeaut, F. \& Delattre O. SWI/SNF chromatin remodeling and human malignancies. Annu. Rev. Pathol. 10, 145-171 (2015).

3. Santen, G. W., Kriek, M. \& van Attikum, H. SWI/SNF complex in disorder: SWItching from malignancies to intellectual disability. Epigenetics 7 , 1219-1224 (2012)

4. Sokpor, G., Xie, Y., Rosenbusch, J. \& Tuoc, T. Chromatin remodeling BAF (SWI/SNF) complexes in neural development and disorders. Front. Mol. Neurosci. 10, 243 (2017)

5. Coffin, G. S. \& Siris, E. Mental retardation with absent fifth fingernail and terminal phalanx. Am. J. Dis. Child. 119, 433-439 (1970).

6. Santen, G. W. et al. Mutations in SWI/SNF chromatin remodeling complex gene ARID1B cause Coffin-Siris syndrome. Nat. Genet. 44, 379-380 (2012).

7. Tsurusaki, Y. et al. Mutations affecting components of the SWI/SNF complex cause Coffin-Siris syndrome. Nat. Genet. 44, 376-378 (2012).

8. Vasileiou, G. et al. Mutations in the BAF-complex subunit DPF2 are associated with Coffin-Siris syndrome. Am. J. Hum. Genet. 102, 468-479 (2018).

9. Wieczorek, D. et al. A comprehensive molecular study on Coffin-Siris and Nicolaides-Baraitser syndromes identifies a broad molecular and clinical spectrum converging on altered chromatin remodeling. Hum. Mol. Genet. 22, 5121-5135 (2013)

10. Bogershausen, N. \& Wollnik, B. Mutational landscapes and phenotypic spectrum of SWI/SNF-related intellectual disability disorders. Front. Mol. Neurosci. 11, 252 (2018).

11. Diets, I. J. et al. A recurrent de novo missense pathogenic variant in SMARCB1 causes severe intellectual disability and choroid plexus hyperplasia with resultant hydrocephalus. Genet. Med. 21, 572-579 (2018).

12. Hodges, C., Kirkland, J. G. \& Crabtree, G. R. The many roles of BAF (mSWI/ SNF) and PBAF complexes in cancer. Cold Spring Harb. Perspect. Med. 6, a026930 (2016). 
13. Guidi, C. J. et al. Disruption of Inil leads to peri-implantation lethality and tumorigenesis in mice. Mol. Cell. Biol. 21, 3598-3603 (2001).

14. Roberts, C. W., Leroux, M. M., Fleming, M. D. \& Orkin, S. H. Highly penetrant, rapid tumorigenesis through conditional inversion of the tumor suppressor gene Snf5. Cancer Cell 2, 415-425 (2002).

15. Tronche, F. et al. Disruption of the glucocorticoid receptor gene in the nervous system results in reduced anxiety. Nat. Genet. 23, 99-103 (1999)

16. Graus-Porta, D. et al. Betal-class integrins regulate the development of laminae and folia in the cerebral and cerebellar cortex. Neuron 31, 367-379 (2001).

17. Kosho, T. \& Okamoto, N. \& Coffin-Siris Syndrome International Collaborators. Genotype-phenotype correlation of Coffin-Siris syndrome caused by mutations in SMARCB1, SMARCA4, SMARCE1, and ARID1A. Am. J. Med. Genet. C. Semin Med Genet 166C, 262-275 (2014).

18. Santen, G. W. et al. Coffin-Siris syndrome and the BAF complex: genotypephenotype study in 63 patients. Hum. Mutat. 34, 1519-1528 (2013).

19. Alcamo, E. A. et al. Satb2 regulates callosal projection neuron identity in the developing cerebral cortex. Neuron 57, 364-377 (2008).

20. Britanova, O. et al. Satb2 is a postmitotic determinant for upper-layer neuron specification in the neocortex. Neuron 57, 378-392 (2008).

21. Suarez, R., Gobius, I. \& Richards, L. J. Evolution and development of interhemispheric connections in the vertebrate forebrain. Front. Hum. Neurosci. 8, 497 (2014).

22. Shu, T., Puche, A. C. \& Richards, L. J. Development of midline glial populations at the corticoseptal boundary. J. Neurobiol. 57, 81-94 (2003).

23. Smith, K. M. et al. Midline radial glia translocation and corpus callosum formation require FGF signaling. Nat. Neurosci. 9, 787-797 (2006).

24. Gobius, I. et al. Astroglial-mediated remodeling of the interhemispheric midline is required for the formation of the corpus callosum. Cell Rep. 17, 735-747 (2016).

25. Kriegstein, A. \& Alvarez-Buylla, A. The glial nature of embryonic and adult neural stem cells. Annu. Rev. Neurosci. 32, 149-184 (2009).

26. Martynoga, B., Drechsel, D. \& Guillemot, F. Molecular control of neurogenesis: a view from the mammalian cerebral cortex. Cold Spring Harb. Perspect. Biol. 4, a008359 (2012).

27. Clegg, J. M. et al. Heparan sulfotransferases Hs6stl and Hs2st keep Erk in check for mouse corpus callosum development. J. Neurosci. 34, 2389-2401 (2014).

28. Conway, C. D. et al. Heparan sulfate sugar modifications mediate be functions of slits and other factors needed for mouse forebrain commissure development. J. Neurosci. 31, 1955-1970 (2011).

29. Pastrana, E., Silva-Vargas, V. \& Doetsch, F. Eyes wide open: a critical review of sphere-formation as an assay for stem cells. Cell Stem Cell 8, 486-498 (2011).

30. Kageyama, R., Ohtsuka, T. \& Kobayashi, T. The Hes gene family: repressors and oscillators that orchestrate embryogenesis. Development 134, 1243-1251 (2007).

31. Wheeler, S. R., Stagg, S. B. \& Crews, S. T. Multiple Notch signaling events control Drosophila CNS midline neurogenesis, gliogenesis and neuronal identity. Development 135, 3071-3079 (2008).

32. Kadam, S. \& Emerson, B. M. Transcriptional specificity of human SWI/SNF BRG1 and BRM chromatin remodeling complexes. Mol. Cell 11, 377-389 (2003).

33. Liddelow, S. A., Dziegielewska, K. M., Vandeberg, J. L. \& Saunders, N. R. Development of the lateral ventricular choroid plexus in a marsupial, Monodelphis domestica. Cereb. Fluid Res. 7, 16 (2010).

34. Cataltepe, O., Liptzin, D., Jolley, L. \& Smith, T. W. Diffuse villous hyperplasia of the choroid plexus and its surgical management. J. Neurosurg. Pediatr. 5, 518-522 (2010).

35. Klochendler-Yeivin, A. et al. The murine SNF5/INI1 chromatin remodeling factor is essential for embryonic development and tumor suppression. $E M B O$ Rep. 1, 500-506 (2000).

36. Roberts, C. W., Galusha, S. A., McMenamin, M. E., Fletcher, C. D. \& Orkin, S. H. Haploinsufficiency of Snf5 (integrase interactor 1) predisposes to malignant rhabdoid tumors in mice. Proc. Natl Acad. Sci. USA 97, 13796-13800 (2000).

37. Guidi, C. J., Veal, T. M., Jones, S. N. \& Imbalzano, A. N. Transcriptional compensation for loss of an allele of the Inil tumor suppressor. J. Biol. Chem. 279, 4180-4185 (2004).

38. Chinn, G. A. et al. Agenesis of the corpus callosum due to defective glial wedge formation in Lhx2 mutant mice. Cereb. Cortex 25, 2707-2718 (2015).

39. Shu, T., Butz, K. G., Plachez, C., Gronostajski, R. M. \& Richards, L. J. Abnormal development of forebrain midline glia and commissural projections in Nfia knock-out mice. J. Neurosci. 23, 203-212 (2003).

40. Piper, M. et al. Multiple non-cell-autonomous defects underlie neocortical callosal dysgenesis in Nfib-deficient mice. Neural Dev. 4, 43 (2009).
41. das Neves, L. et al. Disruption of the murine nuclear factor I-A gene (Nfia) results in perinatal lethality, hydrocephalus, and agenesis of the corpus callosum. Proc. Natl Acad. Sci. USA 96, 11946-11951 (1999).

42. Steele-Perkins, G. et al. The transcription factor gene Nfib is essential for both lung maturation and brain development. Mol. Cell. Biol. 25, 685-698 (2005).

43. Celen, C. et al. Aridlb haploinsufficient mice reveal neuropsychiatric phenotypes and reversible causes of growth impairment. Elife 6, e25730 (2017).

44. van der Sluijs, E. P. J. et al. The ARID1B spectrum in 143 patients: from nonsyndromic intellectual disability to Coffin-Siris syndrome. Genet. Med. 21, 1295-1307 (2018).

45. Sevenet, N. et al. Constitutional mutations of the hSNF5/INI1 gene predispose to a variety of cancers. Am. J. Hum. Genet. 65, 1342-1348 (1999).

46. Hulsebos, T. J. et al. Germline mutation of INI1/SMARCB1 in familial schwannomatosis. Am. J. Hum. Genet. 80, 805-810 (2007).

47. Smith, M. J. et al. Expression of SMARCB1 (INI1) mutations in familial schwannomatosis. Hum. Mol. Genet. 21, 5239-5245 (2012).

48. Swensen, J. J. et al. Familial occurrence of schwannomas and malignant rhabdoid tumour associated with a duplication in SMARCB1. J. Med. Genet. 46, 68-72 (2009).

49. Eaton, K. W., Tooke, L. S., Wainwright, L. M., Judkins, A. R. \& Biegel, J. A. Spectrum of SMARCB1/INI1 mutations in familial and sporadic rhabdoid tumors. Pediatr. Blood Cancer 56, 7-15 (2011).

50. Kehrer-Sawatzki, H. et al. Co-occurrence of schwannomatosis and rhabdoid tumor predisposition syndrome 1. Mol. Genet. Genomic Med. 6, 627-637 (2018).

51. Gossai, N., Biegel, J. A., Messiaen, L., Berry, S. A. \& Moertel, C. L. Report of a patient with a constitutional missense mutation in SMARCB1, Coffin-Siris phenotype, and schwannomatosis. Am. J. Med. Genet. A 167A, 3186-3191 (2015).

52. Gessi, M., Giangaspero, F. \& Pietsch, T. Atypical teratoid/rhabdoid tumors and choroid plexus tumors: when genetics "surprise" pathology. Brain Pathol. 13, 409-414 (2003).

53. Sevenet, N. et al. Spectrum of hSNF5/INI1 somatic mutations in human cancer and genotype-phenotype correlations. Hum. Mol. Genet. 8, 2359-2368 (1999).

54. Taylor, M. D. et al. Familial posterior fossa brain tumors of infancy secondary to germline mutation of the hSNF5 gene. Am. J. Hum. Genet. 66, 1403-1406 (2000).

55. Zakrzewska, M. et al. Mutational analysis of hSNF5/INI1 and TP53 genes in choroid plexus carcinomas. Cancer Genet. Cytogenet. 156, 179-182 (2005).

56. Weber, M., Stockhammer, F., Schmitz, U. \& von Deimling, A. Mutational analysis of INI1 in sporadic human brain tumors. Acta Neuropathol. 101, 479-482 (2001).

57. Judkins, A. R. et al. INI1 protein expression distinguishes atypical teratoid/ rhabdoid tumor from choroid plexus carcinoma. J. Neuropathol. Exp. Neurol. 64, 391-397 (2005).

58. Gessi, M., Koch, A., Milde, U., Wiestler, O. D. \& Pietsch, T. Analysis of hSNF5/INI-1 and TP53 in choroid plexus tumors. Proc. Am. Assoc. Cancer Res. 43, 1138 (2002).

59. Ng, J. M. et al. Generation of a mouse model of atypical teratoid/rhabdoid tumor of the central nervous system through combined deletion of Snf5 and p53. Cancer Res. 75, 4629-4639 (2015).

60. Vitte, J., Gao, F., Coppola, G., Judkins, A. R. \& Giovannini, M. Timing of Smarcb1 and Nf2 inactivation determines schwannoma versus rhabdoid tumor development. Nat. Commun. 8, 300 (2017).

\section{Acknowledgements}

We are grateful to the families for participating in this study. We thank Michaela BeckerRöck, Meike Stotz-Reimers, and Michael Wolf for excellent technical help. Thanks to Dorothea Schulte for very valuable comments on the text and figures. We thank Hermann-Josef Lüdecke for providing molecular data, and Sophie Hinreiner for excellent education of Linda Rey. This work was supported by the German Ministry of Education and Research in the frame of the E-RARE network CRANIRARE-2 to D.W. (BMBF 01GM1211B) and the Chromatin-Net consortium to D.W. (BMBF 01GM1520B). M.B.L received a stipend from the German Research Foundation (GRK 1657).

\section{Author contributions}

A.F. designed and performed experiments, analyzed data, and wrote the paper; L.K.R. analyzed patient data and wrote the paper; M.B.L. performed experiments, analyzed data, and reviewed the manuscript text; M.H., R.P., K.S., and G.W.E.S. collected and analyzed patient data and reviewed the manuscript text; J.S. analyzed MRI scans and wrote the paper; D.W. analyzed patient data and wrote the paper; U.A.N. initiated the study, designed and performed experiments, analyzed data, and wrote the paper. 


\section{Additional information}

Supplementary Information accompanies this paper at https://doi.org/10.1038/s41467019-10849-y.

Competing interests: The authors declare no competing interests.

Reprints and permission information is available online at http://npg.nature.com/ reprintsandpermissions/

Peer review information: Nature Communications thanks the anonymous reviewer(s) for their contribution to the peer review of this work. Peer reviewer reports are available

Publisher's note: Springer Nature remains neutral with regard to jurisdictional claims in published maps and institutional affiliations. (c) Open Access This article is licensed under a Creative Commons Attribution 4.0 International License, which permits use, sharing, adaptation, distribution and reproduction in any medium or format, as long as you give appropriate credit to the original author(s) and the source, provide a link to the Creative Commons license, and indicate if changes were made. The images or other third party material in this article are included in the article's Creative Commons license, unless indicated otherwise in a credit line to the material. If material is not included in the article's Creative Commons license and your intended use is not permitted by statutory regulation or exceeds the permitted use, you will need to obtain permission directly from the copyright holder. To view a copy of this license, visit http://creativecommons.org/ licenses/by/4.0/

(C) The Author(s) 2019 